\title{
GENDER DISCRIMINATION ESTIMATION IN A SEARCH MODEL WITH MATCHING AND BARGAINING*
}

\author{
BY LUCA FLABBI ${ }^{1}$
}

\author{
Georgetown University, U.S.A., and IZA
}

\begin{abstract}
This article develops a search model of the labor market with matching, bargaining, and employers' taste discrimination in which - under necessary but standard distributional assumption-it is possible to separately identify gender discrimination and unobserved productivity differences. The equilibrium shows that both prejudiced and unprejudiced employers wage discriminate. Maximum likelihood estimates on CPS data indicate that half of the employers are prejudiced, average female productivity is $6.5 \%$ lower, and two-third of the gender earning differential may be explained by prejudice. An affirmative action policy is implemented resulting in a redistribution of welfare from men to women at no cost for employers' welfare.
\end{abstract}

\section{INTRODUCTION}

Gender differentials in the labor market are widespread and persistent ${ }^{2}$ : Even if wages and earnings for women and men in the United States have experienced a significant convergence in the 1970s and 1980s, their ratio has remained roughly constant at $75 \%$ since the mid-1990s (Blau and Kahn, 2004; Eckstein and Nagypal, 2004). The United States is not an exception among OECD countries: they rank more or less average, with Northern European countries traditionally showing the lowest differentials and Japan the highest. These differentials persist after conditioning on observable productivity characteristics, and the consensus in the literature is that a significant portion of the conditional differential remains "unexplained."

This type of evidence, together with employment differentials and segregation by industry and occupation, has long been considered a possible indication of prejudice against women in the labor market. However, the observables used to proxy productivity are not an exhaustive description of actual productivity, and, as a result, there is no conclusive evidence on whether gender differentials are due to labor market discrimination or to unobserved productivity differences. The issue can be interpreted as an identification problem: We systematically observe an empirical evidence for which there are competing explanations. One explanation involves prejudice and discrimination, the other differences in workers' behavior, productivity, and preferences.

The contribution of this article is to develop a model of the labor market that allows for discrimination and to show that, using the model and standard distributional assumptions, it

\footnotetext{
* Manuscript received October 2006; revised December 2008.

${ }^{1}$ I would like to thank Chris Flinn for his guidance and constant encouragement. I would also like to thank for highly valuable supervision Raquel Fernandez and Ricardo Lagos and for helpful comments Jim Albrecht, Alberto Bisin, Daniele Checchi, Xiaohong Chen, Daniela Del Boca, Paolo Dudine, Hanming Fang, Anna Fruttero, Chris Ferrall, Andrea Ichino, Boyan Jovanovic, Mike Keane, Donghoon Lee, Alessandro Lizzeri, James Mabli, Francesc Ortega, Vincenzo Quadrini, Shannon Seitz, Giorgio Topa, Frank Vella, Gianluca Violante, Susan Vroman, and participants at seminars in the following Universities: NYU, Georgetown, Yale, Wisconsin-Madison, Penn State, UC-Riverside, Rutgers, Milan, and Northwestern; and at the following conferences: 2005 Duke Conference on Structural Models, 2005 EEA, 2004 SED, 2003 ESPE, 2003 NASM of the Econometric Society. An editor and two referees have been extremely helpful in improving the article. All errors are my own. Please address correspondence to: Luca Flabbi, Georgetown University, Department of Economics, 37th \& O Streets, NW, Washington, DC 20057, U.S.A. Phone: 202-687-6213. Fax: 202-687-6102. E-mail: lf74@georgetown.edu.

${ }^{2}$ For surveys of this evidence and more see Eckstein and Nagypal (2004), Blau and Kahn (2000, 2003, 2004), Altonji and Blank (1999), a special 1998 issue of the Journal of Economic Perspective, and Cain (1986).
} 
is possible to separately identify discrimination from unobserved productivity differences. This identification strategy is then implemented. The model is estimated by maximum likelihood using data from the 1995 Current Population Survey (CPS). The point estimates are used to decompose the contribution of discrimination and other sources of heterogeneity to the overall labor market gender differential and to perform policy experiments.

The model developed in the article posits a labor market characterized by search frictions and employer discrimination in the form of taste discrimination. Taste discrimination is probably the most prominent theory of prejudiced behavior, and its incorporation within a search model of labor market dynamic has already been suggested as a promising way to study the issue (Heckman, 1998; Altonji and Blank, 1999) In the model, there are four types of agents: two types of workers (male and female) and two types of employers (prejudiced and unprejudiced). Workers search for jobs and employers post vacancies. Upon meeting, they observe a match-specific value of productivity and engage in bargaining to determine wages; matching and bargaining generate spillover effects. These effects represent a crucial channel of the transmission of prejudiced behavior on labor market outcomes that has not been captured by the previous applied literature. Spillover effects imply that the existence of a positive proportion of prejudiced employers lowers women's outside option; as a result, women experience wage discrimination not only from prejudiced employers but also from unprejudiced employers.

Using data on accepted wages and unemployment durations, this model allows for the separate identification of prejudice and unobserved productivity differences under a relatively large class of distributional assumptions. However, it is worth emphasizing that a distributional assumption is necessary for model identification. This major limitation is shared by most search models (Flinn and Heckman, 1982) and the added value here is that the same restriction is enough to also identify discrimination. The identification strategy exploits a distinctive feature of the observed earnings distribution of women with respect to men: Female earnings are more concentrated in the left tail and the density to the left of the mode is quite flat. ${ }^{3}$ The model also generates this difference in shape because the observed female earnings distribution is a mixture between two earnings distributions: one composed by women working for unprejudiced employers and the other by women working for prejudiced employers.

The estimates are obtained by maximum likelihood using data from the 1995 CPS. CPS has been chosen because this allows for disaggregation by relatively homogenous subgroups and the year 1995 because it is in the middle of a period of relative stability of gender differentials. Results show that both discrimination and productivity differences are present in the labor market for white college graduates. Average female productivity is estimated to be about $6.5 \%$ lower than male productivity, and explicit prejudice is estimated to involve about half of the employers. Using these estimated structural parameters, it is possible to decompose the observed earnings differential, taking into account equilibrium effects. The resulting decomposition shows that prejudice is the most important factor in explaining the differential but that productivity also plays a significant role. Prejudice is able to generate up to two-thirds of the observed earnings differential, whereas differences in productivity generate up to one-third.

I also consider the scope for Affirmative Action policies. I first show that an affirmative action policy implemented as a quota system has no impact under the parameter estimates, because a significant proportion of women are already hired in the pre-policy equilibrium. I then implement an affirmative action policy defined as an employer's subsidy for hiring women. The policy generates a redistribution of welfare from men to women without significantly changing employers' welfare.

Although a large literature shares the same objective as this article, very few implement a similar approach. The main example is Bowlus and Eckstein (2002), an equilibrium search

\footnotetext{
${ }^{3}$ See Figures 1 and 2, below. The literature usually focuses on differences in means, but this difference in shape is quite general and it is not specific to the year and sample used here. For example a similar shape is found on CPS data for 1985 and 2005 (the first and last year on which a similar sample can be extracted), and a similar pattern can be implied from the empirical cumulative density functions in Bowlus (1997) on data from NLSY.
} 
model with employer's taste discrimination against black workers. Their results indicate that the importance of productivity differences in explaining race wage differentials is significantly reduced when explicit discrimination is considered. However, the focus of their paper is more on proposing an identification strategy than on providing reliable estimates. As a result, maximum likelihood estimation is not applicable and the estimates are not robust when both discrimination and productivity differences are assumed. In this respect, my article has the advantage of obtaining maximum likelihood estimates by adopting a different identification strategy. This comes at the theoretical cost of assuming an exogenous distribution of match-specific productivity. Nonetheless, the bargaining structure that I am considering in the model adds new equilibrium effects that turn out to be quite relevant.

Two other prominent examples in a similar line of research are Eckstein and Wolpin (1999) and Bowlus (1997). Eckstein and Wolpin (1999) use the bargaining structure in a search model to obtain bounds on the amount of racial discrimination. However, the bounds they obtain on 1979 NLSY data turn out to not be informative. Bowlus (1997) is the only contribution in the related search literature focusing on gender differentials. However, she does not allow for discrimination, thus estimating large differences in unobserved productivity between men and women. As the author acknowledges, unobserved productivity is forced in her model to explain all the residual differential in wages.

With respect to the general literature on discrimination, it is worth noticing that only one of the two possible theories of discrimination is allowed in the model: taste discrimination (Becker, 1971). The alternative theory, statistical discrimination, ${ }^{4}$ is ruled out by the fact that matchspecific productivity is common knowledge to both the worker and the employer. Removing this restriction would make the model impossible to identify, but the "spillover effects" present in the model share a similar mechanism with the standard statistical discrimination theory: In equilibrium, group characteristics affect individual level wage schedules. Recent applications of statistical discrimination to gender labor market differentials are Gayle and Golan (2008) and Albanesi and Olivetti (2009). Interestingly, Gayle and Golan (2008) estimate an impact of discrimination on wage differential of a magnitude similar to that found in this article.

The article is organized as follows. Section 2 presents the model and its main implications. Section 3 describes the data and the procedure to extract the estimation sample. Section 4 derives the likelihood function and the identification strategy. Section 5 reports and discusses the estimation results. Section 6 contains the policy experiments based on the estimated parameters. Section 7 discusses some major limitations of the article and proposes future research. Finally, Section 8 summarizes the main conclusions.

\section{THE MODEL}

The search model with matching and bargaining used in this article is a fairly standard framework used to study labor market dynamics. ${ }^{5}$ It is a tractable improvement on partial equilibrium job search models, allowing for a wider range of equilibrium effects once major policy or structural changes are introduced. Search-matching-bargaining models have been estimated to study a variety of issues, such as duration to first job and returns to schooling (Eckstein and Wolpin, 1995), race discrimination (Eckstein and Wolpin, 1999), and the impact of mandatory minimum wage (Flinn, 2006).

A theory of taste discrimination was first proposed by Gary Becker in 1957 (last published as Becker, 1971) The idea is to relate prejudiced behavior to preferences that economic agents may have with respect to clearly identified groups. Taste discrimination is still the most widespread, albeit debated, theory of prejudiced behavior, and search models are a promising way to

\footnotetext{
${ }^{4}$ Arrow (1973) and Phelps (1972). A recent application using an interesting way to identify statistical discrimination by imposing model restrictions is Moro (2003).

${ }^{5}$ Jovanovic (1979) gives theoretical foundation to the importance of match-specific productivity in explaining labor market dynamics. Flinn and Heckman (1982) provide the basic theory for identification.
} 
extend Becker's theory of discrimination because the monopsony power induced by search frictions generate positive profits. Some employers can then choose to "indulge" in their prejudice according to their preferences (Heckman, 1998), generating the persistent discrimination that we seem to observe (Altonji and Blank, 1999).

2.1. Environment. The model is in continuous time, populated by four types of agents infinitely lived: two types of workers (men and women) and two types of employers (prejudiced and unprejudiced). The proportion of prejudiced employers is indicated with $p$ and the proportion of male workers is denoted by $m$, and they are both common knowledge to all the agents. Workers meet employers following a Poisson process with an instantaneous rate of arrival $\lambda$. The search process is random, ${ }^{6}$ and there is no on-the-job search. Once an employer and a worker meet, they observe a match-specific productivity value $(x)$, modeled as a draw from an exogenous distribution denoted by the cdf $G$. Once a match is formed, it can be terminated following a Poisson process at an instantaneous rate $\eta$.

Wages are determined through wage bargaining between employers and workers upon observing the match value and their types. Workers' utility functions are linear in wages and no disutility from working is assumed. While unemployed, workers receive an instantaneous utility (or disutility) flow $b$. The last exogenous common knowledge parameter in the model is a discount rate $\rho$, assumed to be the same for employers and workers.

The workers' type is defined by an observable characteristic (gender) that induces a different behavior in the employer the worker is meeting. The two groups of workers may also have ex ante differences in some of the fundamental parameters that explain the labor market dynamic such as the arrival rate and the productivity distribution. In the theoretical presentation of the model, though, the productivity distribution and all the exogenous transition rates are assumed to be the same for the two groups. This " homogenous" formulation allows for a concise presentation of the model. It also shows that the presence of prejudiced employers is enough to replicate the descriptive empirical evidence we observe. Heterogeneity will then be introduced in the empirical section to estimate specifications that include both prejudice and gender differentials in productivity and behavior.

The employers' type is defined by a difference in preferences: prejudiced employers receive a disutility flow $(d)$ from hiring women (Becker, 1971). Employers maximize utility, there are constant returns to scale, and labor is the only factor of production. Therefore, the total output at a given employer is the sum of the productivity levels $(x)$ of all his/her matched employees. Employers earn no revenues but make no payment if a match is not realized; therefore the value of their outside option is zero.

2.2. Value Functions. Unprejudiced and prejudiced employers are denoted by $I=N, P$, and male and female workers are denoted by $J=M, W$. The detailed derivation of the value functions is presented in Appendix A1 whereas in the following only a brief description of them is provided. The value of employment for a worker of type $J$ working at an employer of type $I$ at a wage $w_{J I}(x)$ is

$$
W_{J}\left[w_{J I}(x)\right]=\frac{w_{J I}(x)+\eta U_{J}}{\rho+\eta} .
$$

Equation (1) states that the value of employment is the current instantaneous value of the state for the worker $\left(w_{J I}(x)\right)$ plus the value of the other possible state (unemployment, $U_{J}$ ) weighted by the probability associated to this event $(\eta)$, all appropriately discounted by the instantaneous rates $\rho$ and $\eta$.

\footnotetext{
${ }^{6}$ It may seem more realistic to introduce directed search in this context, as, for example, in Mailath et al. (2000). However, the focus of the article is on the empirical prediction of the model, and, given the data at hand, it does not make an identifiable difference to assume exogenously different arrival rates, as it is done in the empirical implementation of the model, or to model directed search behavior. Notice that the rate of arrival of offers from the two types of employers is allowed to be different because the proportion of the two types of employers is not necessarily the same.
} 
While unemployed, a potential worker receives instantaneous (dis)utility from unemployment (b), and, as a result of the search activity, three main events may happen: not meeting any firm, meeting a prejudiced employer, or meeting an unprejudiced employer. By stationarity and by the Poisson processes governing meetings and terminations, the value of unemployment for a worker of type $J$ is then given by

$$
\begin{aligned}
\rho U_{J}=b+\lambda & \left\{p \int \max \left[W_{J}\left[w_{J P}(x)\right]-U_{J}, 0\right] d G(x)\right. \\
& \left.+(1-p) \int \max \left[W_{J}\left[w_{J N}(x)\right]-U_{J}, 0\right] d G(x)\right\}
\end{aligned}
$$

Equation (2) shows that the value of unemployment is constant with respect to wages and has the usual interpretation: The reservation wage should compensate the state of unemployment with expected gains from matching with a prejudiced or an unprejudiced employer.

These two value functions show that the optimal decision rule will have a reservation value property: Because the value of employment is increasing in $w$, whereas the value of unemployment is constant in $w$, a reservation wage $w^{*}$ will exist such that $W_{J}\left[w_{J}^{*}\right]=\rho U_{J}$. However, the next section will show that wages are a monotone function of the match-specific productivity $x$, and therefore the relevant type-specific reservation values will be defined over $x$.

2.3. Wages. When employers and workers meet, the value of the match and the types are fully revealed. Common knowledge of the matching value is the usual practice in these models, and it rules out the possibility of statistical discrimination.

Wages are determined by bargaining upon observing the match-specific productivity and the types. The axiomatic Nash bargaining solution is assumed, and therefore wage schedules are determined by choosing a wage that maximizes the product of the surplus in the match of the two agents, weighted by their relative bargaining power coefficient. The workers' surplus is given by the difference between the value of accepting the job, $W_{J}\left(w_{J I}\right)$, and the value of the alternative, $U_{J}$. The employer's surplus is given by the discounted profit plus, in the case of prejudiced employers, the disutility from hiring women.

Using Equations (1) and (2), Nash bargaining implies

$$
\begin{aligned}
w_{J I}\left(x, U_{J}\right) & =\arg \max _{w}\left\{\frac{\left[w-\rho U_{J}\right]^{\alpha}\left[x-d \mathbf{I}_{\{W, P\}}-w\right]^{(1-\alpha)}}{\rho+\eta}\right\} \\
& \Longrightarrow w_{J I}\left(x, U_{J}\right)=\alpha\left(x-d \mathbf{I}_{\{W, P\}}\right)+(1-\alpha) \rho U_{J},
\end{aligned}
$$

where $\mathbf{I}_{\{W, P\}}$ is an indicator function equal to one when the worker is female $(J=W)$ and the employer prejudiced $(I=P)$. A behavioral interpretation of this solution is that it is unique subgame perfect equilibrium of the basic alternating offer game over dividing the surplus, in continuous time. Under this interpretation, the common discount value for all the agents implies that also the bargaining power coefficients are the same, ${ }^{7}$ that is, $\alpha=1 / 2$.

In terms of agents' types, four matches are possible: men with prejudiced or unprejudiced employers and women with prejudiced or unprejudiced employers. The corresponding wage schedules can be obtained from Equation (3).

A man matched with an unprejudiced or a prejudiced employer, $I=N, P$, will receive

$$
w_{M I}\left(x, U_{M}\right)=\alpha x+(1-\alpha) \rho U_{M} .
$$

The first line of Equation (4) states that the wage of a realized match should guarantee the worker the reservation value $\rho U_{M}$ plus a portion $\alpha$ of the total surplus of the match, that is,

${ }^{7}$ See Binmore et al. (1986) and Binmore (1987). 
$\left(x-\rho U_{M}\right)$. Note that the wage schedule is independent of the employer's type and induces a reservation value on the productivity of the match. This is the truly relevant reservation value, because both reservation wages and reservation profits depend on the match productivity value. The match reservation value is such that $W_{M}\left[w_{M J}\left(x_{M J}^{*}, U_{M}\right)\right]=U_{M}$ and $\pi_{J M}\left(x_{J M}^{*}, U_{M}\right)=0$. Using (1)-(3), it is determined to be

$$
x_{M J}^{*}=x_{J M}^{*}=\rho U_{M} \Longrightarrow w_{M J}^{*}=\rho U_{M} .
$$

This is the value above which both the employer and the worker agree to enter the match. This nondisagreement result is an implication of the Nash bargaining assumption as shown by the first-order condition of the maximization problem in Equation (3).

A woman matched with an unprejudiced or a prejudiced employer, $I=N, P$, will receive

$$
w_{W I}\left(x, U_{W}\right)=\alpha\left(x-d \mathbf{I}_{\{W, P\}}\right)+(1-\alpha) \rho U_{W} .
$$

Equation (5) has the same interpretation of Equation (4), but now the wage schedule depends on the employer's type. Matching with a prejudiced employers will shift down the wage schedule, thus creating wage discrimination with respect to women working for an unprejudiced employers. Proposition 1 will prove that also wage discrimination with respect to men is present due to the lower female value of unemployment in equilibrium. As before, the nondisagreement point is determined by equating the values of the two possible states for workers and employers, leading to

$$
x_{W I}^{*}=x_{I W}^{*}=\rho U_{W}+d \mathbf{I}_{\{W, P\}} \Longrightarrow w_{W J}^{*}=\rho U_{W} .
$$

Therefore, even if the reservation wage is the same for all the female workers, the reservation productivity value is higher for women matched with prejudiced employers. A woman is more picky to accept a job from a prejudiced than from an unprejudiced employer. She will accept, though, if the value of the match is high enough because wages are increasing in productivity. A symmetric argument holds for the prejudiced employer because profits also are increasing in productivity. $^{8}$

2.4. Equilibrium and Model Implications. Using Equations (1), (2), and (3), the values of unemployment $U_{J}$ are implicitly determined by

$$
\begin{aligned}
\rho U_{J}=b+\frac{\lambda \alpha}{\rho+\eta}\left\{p \int_{\rho U_{J}+d \mathbf{I}_{\{W\}}}\left[x-d \mathbf{I}_{\{W\}}-\rho U_{J}\right] d G(x)\right. \\
\\
\left.+(1-p) \int_{\rho U_{J}}\left[x-\rho U_{J}\right] d G(x)\right\}, J=M, W .
\end{aligned}
$$

The equilibrium is therefore defined as

Definition 1. Given a vector $(\lambda, \eta, \rho, b, \alpha, d, p)$ and a probability distribution function for productivity of match values $G(x)$, an equilibrium is a vector of values of unemployment $U^{*}=$ $\left(U_{M}^{*}, U_{W}^{*}\right)$ that solves Equations $(6)$ for $J=M, W$. The equilibrium vector $U^{*}$ determines all the reservation values that constitute each agent's decision rules.

An important implication of this equilibrium concerns the value of unemployment for the two types of workers. What we expect is a lower value of unemployment for women because a

\footnotetext{
${ }^{8}$ Notice also that when female workers have all the bargaining power $(\alpha=1)$, they pay all the cost of discrimination as measured by the disutility $d$. If this is the case, a complete segregation result is likely to occur.
} 
positive measure of prejudiced employers worsens their perspectives in the labor market. This result is stated in the following proposition. ${ }^{9}$

Proposition 1. For any equilibrium previously defined such that $0<p \leq 1$ and $d>0$, the value of unemployment for women is lower than for men, that is,

$$
U_{W}<U_{M}
$$

The main empirical motivation of the labor market discrimination debate is the presence of gender differentials in unconditional or conditional means of some measure of wages. These differentials should proxy different wage rates for equally productive workers. Different wages at same productivity is the usual definition of wage discrimination. A further empirical evidence that is often considered is segregation, defined as the concentration of minority workers in relatively few sectors of the economy. It is useful to define both concepts within the model to clarify the implications of the equilibrium for the empirical evidence.

Definition 2. In the economy defined earlier, workers' type $J$ suffers wage discrimination with respect to workers' type $J^{\prime}$ if and only if they are paid a lower wage conditioning on same productivity, that is,

$$
w_{J I}(x)-w_{J^{\prime} I}(x)<0 \text { for any productivity value } x \text {. }
$$

Definition 3. In the economy defined earlier, complete segregation means that all workers of type $J$ work for employers of type I; partial segregation means that workers of type $J$ work in higher proportion for employers of type $I$.

Using these definitions and Proposition 1 is possible to study the equilibrium effects of prejudice on employers that are not prejudiced showing that prejudice and wage discrimination are two separate concepts, even if they quite often overlap. Wage discrimination may simply be a best response in a given environment, without any implication in terms of preferences. Moreover, wage discrimination disjoint from prejudice has different policy implications than a situation in which wage discrimination and prejudice coincide. In this respect, an interesting case described by the model is the behavior of unprejudiced employers that discriminate against women because the presence of prejudiced employers worsens the bargaining position of women. This situation is summarized in the following definition.

Definition 4. In the economy defined earlier, spillover effects means that the presence of prejudiced employers induces wage discrimination also at unprejudiced employers, that is,

$$
w_{J N}(x)-w_{J^{\prime} N}(x)<0 \text { for any productivity value } x \text {. }
$$

It is now possible to summarize the implications of the model with respect to the descriptive evidence on gender differentials in the labor market. The evidence can be summarized as (i) male average earnings higher than female average earnings and (ii) some degree of concentration of women in some sectors and occupations, that is, partial but not complete segregation. These implications can be directly derived from Proposition 1 as shown in Appendix A2.

Notice that wage differentials in the model arise from two channels. First, women working for a prejudiced employers will be paid less than a men equally productive. Second, the presence of a positive proportion of prejudiced employers implies in equilibrium a lower value of entering the labor market for women. This value is proportional to the threat point of women while bargaining with any employer. Therefore, even when working for an unprejudiced employer,

\footnotetext{
${ }^{9}$ All the proofs are in Appendix A2.
} 
women will receive lower wages at the same level of productivity because they are less able to extract rent when bargaining for wages. ${ }^{10}$

The relevant question is now empirical: How important is the impact of prejudice when other sources of heterogeneity are present? In particular, if men and women differs in ex ante productivity and search behavior, to what extent is prejudice still a major factor in explaining gender differentials in the labor market? The result depends on parameter values, and the objective of the estimation section is to obtain these values for a representative sample of U.S. workers. Notice also that the structure of the model may offer a different and richer reading of the empirical evidence. For example, estimating a conditional mean wage differential may overestimate prejudice because also unprejudiced employers wage-discriminate women; on the other side, the direct observation of prejudice may underestimate its impact on welfare because of spillover effects.

\section{DATA}

The sample used in estimation is extracted from the Annual Social and Economic Supplement (March Supplement) of the Current Population Survey (CPS) for the year 1995. A more detailed description of the Survey and the sample extraction procedure can be found in Appendix A3. CPS has been chosen because it is a very large nationally representative sample that permits disaggregation by relatively homogenous subgroups. The year 1995 was chosen because it is in the middle of a period of relative stability of gender differentials in the labor market. ${ }^{11}$

Individuals in the estimation sample satisfy the following criteria:

- 30-55 years old (extremes included);

- employed or looking for a job;

- classified as white; and

- holding a college degree or more.

These selection criteria are introduced to guarantee a degree of homogeneity in the sample. In the model, workers are assumed to be homogenous with the only exception being gender. Selecting a sample homogenous with respect to some observables correlated with performance in the labor market is a minimum requirement for a meaningful empirical application. Some justification about the homogeneity controls is provided in Appendix A3.

The observed labor market variable used to estimate the likelihood contribution of unemployed individuals is the individual unemployment duration. No wage information for unemployed individuals is available. The final sample contains 49 unemployed individuals, 28 women and 21 men. Some descriptive statistics are reported in Table 1. Women have on average lower unemployment duration but a higher unemployment rate. ${ }^{12}$ The mean and standard deviation of unemployment durations are roughly equal, an indication that the exponential distribution implied by the model is not inconsistent with the data.

The labor market variable observed for employed individuals is earning at the date of the interview. Earnings are recorded before deductions, and, conditioning on the homogeneity controls, the sample contains 1,031 women and 1,244 men with valid observations on hourly earnings. Some descriptive statistics are in the top panel of Table 1.

\footnotetext{
${ }^{10}$ Some episodic evidence is consistent with this interpretation. A typical example is the academic job market (Blau and Kahn, 2000).

${ }^{11}$ For example, Eckstein and Nagypal (2004) assess the U.S. labor market dynamic over 1961-2002 using CPS, and they show that the female-to-male wage ratio has increased substantially from the mid-1970 to the early 1990, starting to fluctuate after the late 1990. Blau and Kahn (2000) show a significant convergence in the 1970 and 1980, with the ratio increasing from about $60 \%$ to about $75 \%$, and then a substantial stability at this level during the 1990 .

12 Bowlus (1997), using a sample from NLSY, finds higher unemployment durations for women. This difference may be due to cohort effects and to the inclusion of transitions from nonparticipation. The participation rate differential for the demographic group considered in this article is not too high: $96.8 \%$ for men and $85.2 \%$ for women.
} 
TABLE 1

DESCRIPTIVE STATISTICS

\begin{tabular}{|c|c|c|c|c|c|c|}
\hline Sample Moments & $N$ & $P(i \epsilon U)$ & $E\left(w_{i} \mid i \epsilon E\right)$ & $S D\left(w_{i} \mid i \epsilon E\right)$ & $E\left(t_{i} \mid i \epsilon U\right)$ & $S D\left(t_{i} \mid i \epsilon U\right)$ \\
\hline \multicolumn{7}{|c|}{ Without trimming } \\
\hline All & 2,324 & 0.0211 & 19.16 & 9.51 & 4.53 & 4.13 \\
\hline Women & 1,059 & 0.0264 & 16.78 & 8.46 & 3.72 & 3.33 \\
\hline Men & 1,265 & 0.0166 & 21.13 & 9.87 & 5.59 & 4.88 \\
\hline $\begin{array}{l}\text { women/men } \\
\text { ratio }\end{array}$ & 0.837 & 1.590 & 0.794 & 0.857 & 0.665 & 0.682 \\
\hline \multicolumn{7}{|c|}{ With trimming } \\
\hline All & 2,213 & 0.0226 & 19.89 & 9.16 & 4.53 & 4.13 \\
\hline Women & 1,009 & 0.0277 & 17.41 & 8.17 & 3.72 & 3.33 \\
\hline Men & 1,204 & 0.0174 & 21.94 & 9.44 & 5.59 & 4.88 \\
\hline $\begin{array}{l}\text { ratio }\end{array}$ & 0.838 & 1.592 & 0.794 & 0.865 & 0.665 & 0.682 \\
\hline
\end{tabular}

Note: Data extracted from the Annual Social and Economic Supplement (March Supplement) of the CPS for the year 1995. Variables definition: $t_{i}$ is the monthly unemployment duration; $w_{i}$ is the hourly earnings in dollars; $i \epsilon U$ is the individual $i$ is unemployed; $i \epsilon E$ is the individual $i$ is employed.

The CPS data include reports of extremely low earnings that may suggest the presence of underreporting: I have therefore chosen to trim the low tail of the two earnings distributions. ${ }^{13}$ The amount of trimming implies a trade-off: The more observations are deleted, the higher is the probability of deleting unrealistically low wages but the higher is the distortion of the earnings distribution, in particular of the female distribution, where many observations are clustered in the low tail. The compromise I have reached is to drop the bottom 5\%, computing the percentile separately on the male and female earning distributions. The $5 \%$ percentile is a standard cutoff point (see, e.g., Bowlus, 1997) and generates minimum earnings equal to 5.75 dollars per hour for women and to 7.175 dollars per hour for men. As will be clear from the identification strategy, the estimation of reservation values is very sensitive to this cutoff point. However, the estimation of the other relevant parameters is not as shown in the estimation section.

A second issue of CPS data is the presence of topcoding of income and earning variables. For my sample, topcoding on hourly earnings is binding only on five observations while topcoding on weekly earnings involves 122 observations. The main problem of topcoding for the estimation of the model is the distortion of the shape of the observed earnings distribution due to the mass points that topcoding naturally generates. Variation in hours worked reduces the impact of topcoding on weekly earnings, generating an empirical earnings distribution with only three mass points of about a dozen observations for men and one mass point for women (Figures 1 and 2) implying a negligible impact on the estimation results.

The sample used for estimation is reported in the lower panel of Table 1 . The earning differential is basically unchanged by the trimming: The female-to-male earnings ratio is $79.4 \%$, a value consistent with data on representative samples for the United States. ${ }^{14}$ This ratio is slightly higher than the one for the whole population: Using CPS, the ratio is $77.07 \%$ over the entire labor force and $74.53 \%$ over whites in the same age range. Male earnings have an higher standard deviation, mainly because female earnings tend to be more clustered in the left tail. The empirical

\footnotetext{
${ }^{13}$ An alternative solution is to explicitly allow for measurement errors in earnings. However, this does not seem the appropriate solution for this specific problem. Allowing for measurement errors in earnings usually has the advantage of taking into account probability-zero events observed in the sample, for example, job-to-job transitions associated with a wage loss in an on-the-job search model (Wolpin, 1987; Flinn, 2002a). This advantage will be absent here, and the efficiency cost of adding measurement errors seems higher than the benefit of keeping these unrealistically low earnings in the sample.

${ }^{14}$ Bowlus (1997) uses NLSY on white college graduates and finds a ratio equal to 0.815 on weekly wages. Without controlling for race, Eckstein and Nagypal (2004) use the annual wages and salary earnings for full-time full-year workers from CPS 1995 and compute a ratio equal to 0.662 on college graduates between the ages of 22 and 65 . Without controlling for race, Blau (1998) uses weekly wage for full-time workers on CPS 1994 and finds a ratio equal to 0.736 on those 35-44 years old with 16 years of education or more.
} 


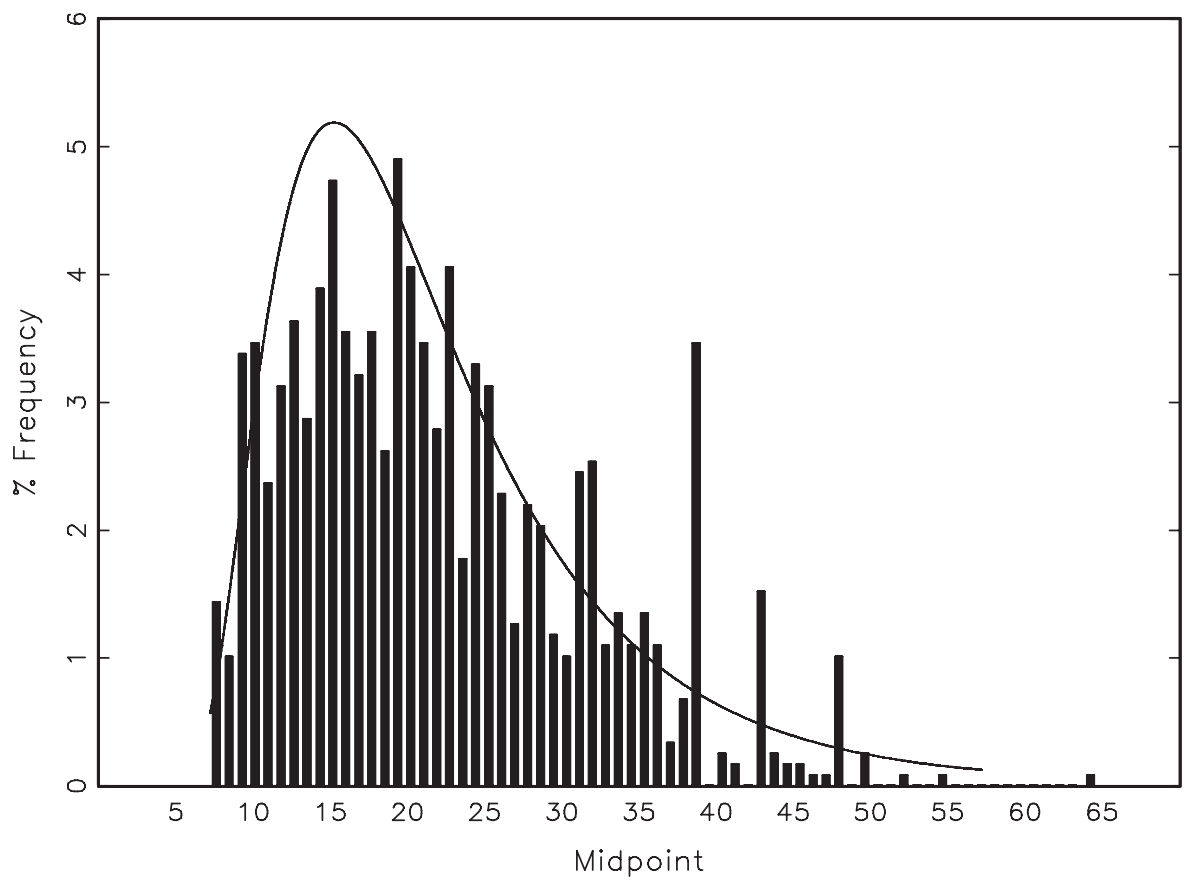

FIGURE 1

EMPIRICAL AND PREDICTED EARNINGS DISTRIBUTION—MEN

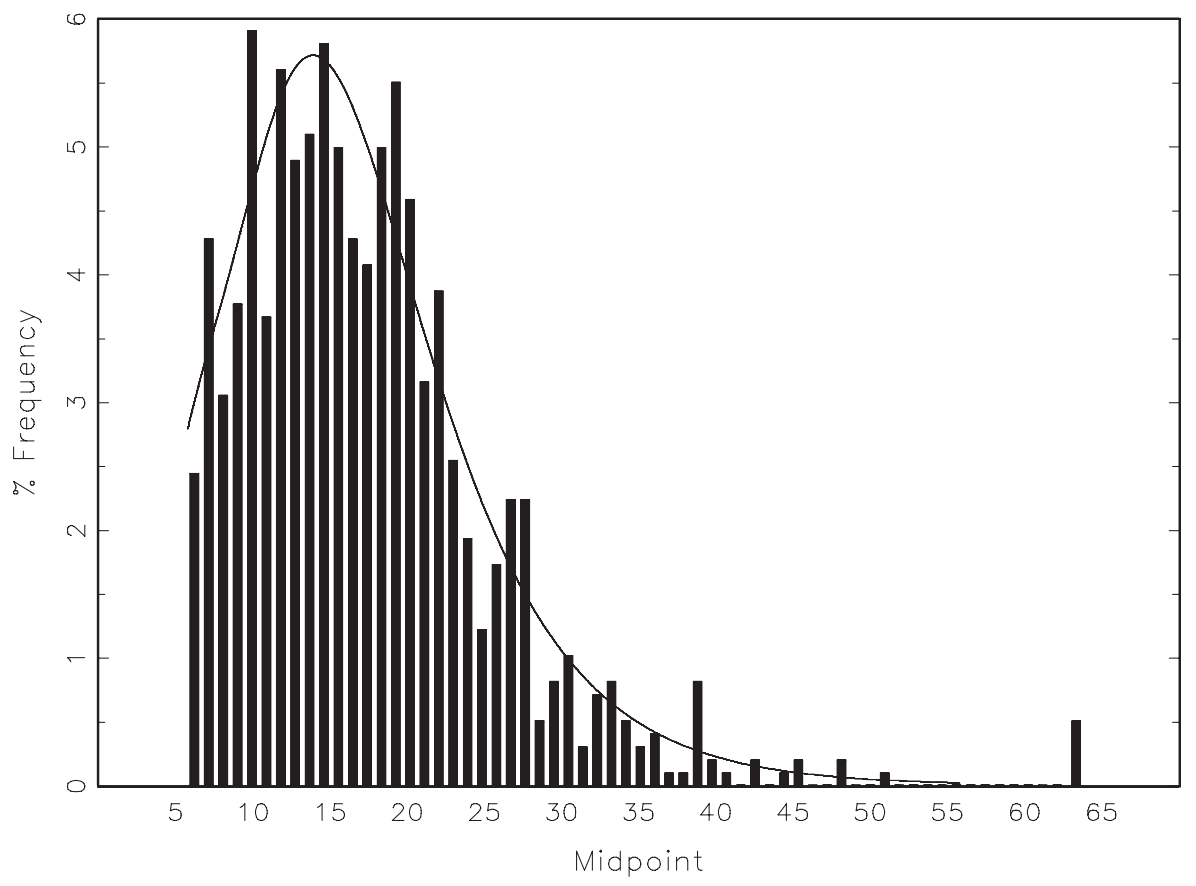

Figure 2

EMPIRICAL AND PREDICTED EARNINGS DISTRIBUTION-WOMEN 
earnings distributions reported in Figures 1 and 2 reveals this clear difference in shape: Female earnings are highly concentrated between the minimum wage and 20 dollar per hour. Also, the slopes of the two densities are quite different: The female density is relatively flat between the truncation point and the mode (in particular if we ignore the spikes due to rounding) and then decreases quite fast after 20 dollar per hour; the male density increases between the truncation point and the mode and smoothly decreases after the 15/20 dollar per hour level.

\section{IDENTIFICATION}

The CPS sample can be described as a vector $\left(\left\{w_{i}\right\}_{i \in E_{J}} ;\left\{t_{i}\right\}_{i \in U_{J}}\right)_{J=M . W}$ where $w_{i}$ are hourly earnings, $t_{i}$ are on-going unemployment durations measured in months, $E_{J}$ is the set of employed individuals of gender $J$, and $U_{J}$ is the set of unemployed individuals of gender $J$.

4.1. Likelihood Function. In the theoretical model presented in Section 2, men and women are identical if no prejudice is present. In the empirical specification, however, it is important to also allow for productivity differences between men and women. Productivity differences are introduced by allowing the parameters of the productivity distribution to differ by gender. Other behavioral differences are captured by gender-specific arrival rates, termination rates, and instantaneous values of unemployment. These describe differences in the intensity of search or in other behaviors related to the labor market search process in a reduced form fashion. The subscript $J=M, W$ is used to denote these differences in parameters together with the notation $I=N, P$ used to indicate employers' heterogeneity.

Using Equations (4), (5), and (6), the model with both workers and employers heterogeneity is summarized by four wage equations,

$$
w_{J I}=\alpha\left(x-d \mathbf{I}_{\{W, P\}}\right)+(1-\alpha) \rho U_{J},
$$

and by two reservation wage equations,

$$
\begin{gathered}
\rho U_{J}=b_{J}+\frac{\lambda_{J} \alpha}{\rho+\eta_{J}}\left\{p \int_{\rho U_{J}+d \mathbf{I}_{\{W\}}}\left[x-d \mathbf{I}_{\{W\}}-\rho U_{J}\right] g_{J}(x) d x\right. \\
\left.+(1-p) \int_{\rho U_{J}}\left[x-\rho U_{J}\right] g_{J}(x) d x\right\},
\end{gathered}
$$

where the corresponding cumulative distribution function for the density $g_{J}(x)$ is indicated by $G_{J}(x)$ and the corresponding survival function by $\tilde{G}_{J}(x)$.

Although the equilibrium of the model implies the same reservation wage at both employers for each type of worker, the reservation match-value for women is higher when they meet prejudiced employers than unprejudiced employers. Specifically, the difference between these two reservation values is exactly equal to the intensity of discrimination $d$.

The likelihood of a sample extracted from this steady state equilibrium is given by the contribution of unemployed and employed individuals. In order to obtain the contribution of unemployed individuals, consider the hazard rate out of unemployment:

$$
h_{J}=\lambda_{J}\left[(1-p) \tilde{G}_{J}\left(\rho U_{J}\right)+p \tilde{G}_{J}\left(\rho U_{J}+d \mathbf{I}_{\{W\}}\right)\right] .
$$

This constant hazard rate is implied by the time homogeneity of the environment, the Poisson process that governs the arrival of job offers, and the optimal decision rule. It is given by two components: the arrival rate of offers and the probability that a match is formed once the meeting occurs. Therefore, men and women may have different hazard rates for exogenous reasonssuch as a different arrival rate-and for endogenous reasons-such as the equilibrium impact of the presence of prejudice on the probability to accept the match. The environment implies 
that the unconditional unemployment contribution over on-going durations is the density of an exponential random variable with coefficient equal to the hazard rate times the steady-state probability of unemployment:

$$
\begin{aligned}
f_{u}\left(t_{i}, i \epsilon U \mid J\right) & =f_{u}\left(t_{i} \mid i \epsilon U, J\right) P(i \epsilon U \mid J) \\
& =h_{J} \exp \left(-h_{J} t_{i}\right) \frac{\eta_{J}}{\eta_{J}+h_{J}}, t_{i}>0 .
\end{aligned}
$$

The probability of unemployment $\left(\frac{\eta_{J}}{\eta_{J}+h_{J}}\right)$ takes into account that durations are observed only for unemployed individuals. The complete derivation of the density (11) is presented in Appendix A4.

The contribution of employed individuals is based on the mapping between wages and match values reported in Equation (8). Starting with the unconditional cumulative distribution function of earnings, the contribution of employed individuals is derived from the optimal decision rules, the parametric assumption on the match distribution, and ergodic results on flows in and out employment. This derivation, presented in Appendix A4, leads to the following contribution for observed earnings:

$$
\begin{aligned}
& f_{e}\left(w_{i}, w_{i}>\rho U_{J}, i \epsilon E \mid J\right) \\
& \quad=f_{e}\left(w_{i} \mid w_{i}>\rho U_{J}, i \epsilon E, J\right) P\left(w_{i}>\rho U_{J} \mid i \epsilon E, J\right) P(i \epsilon E \mid J) \\
& \quad=\left[\frac{\frac{(1-p)}{\alpha} g_{J}\left(\frac{w_{i}-(1-\alpha) \rho U_{J}}{\alpha}\right)}{\tilde{G}_{J}\left(\rho U_{J}\right)}+\frac{\frac{p}{\alpha} g_{J}\left(\frac{w_{i}+\alpha d \mathbf{I}_{\{W\}}-(1-\alpha) \rho U_{J}}{\alpha}\right)}{\tilde{G}_{J}\left(\rho U_{J}+d \mathbf{I}_{\{W\}}\right)}\right] \frac{h_{J}}{h_{J}+\eta_{J}}, w_{i}>\rho U_{J} .
\end{aligned}
$$

Based on these densities, the log-likelihood can be written as

$$
\begin{aligned}
\ln L(\Omega ; w, t)= & N_{M} \ln \frac{h_{M}}{h_{M}+\eta_{M}}+N_{U M} \ln \eta_{M} \\
& -h_{M} \sum_{i \in U_{M}} t_{i}+\sum_{i \in E_{M}} \ln \frac{\frac{1}{\alpha} g_{M}\left(\frac{w_{i}-(1-\alpha) \rho U_{M}}{\alpha}\right)}{\tilde{G}_{M}\left(\rho U_{M}\right)}+N_{W} \ln \frac{h_{W}}{h_{W}+\eta_{W}} \\
& +N_{U W} \ln \eta_{W}-h_{W} \sum_{i \in U_{W}} t_{i}+\sum_{i \in E_{W}} \ln \left[\begin{array}{c}
\frac{(1-p)}{\alpha} g_{W}\left(\frac{w_{i}-(1-\alpha) \rho U_{W}}{\alpha}\right) \\
\frac{\tilde{G}_{W}\left(\rho U_{W}\right)}{\alpha} g_{W}\left(\frac{w_{i}+\alpha d-(1-\alpha) \rho U_{W}}{\alpha}\right)
\end{array},\right.
\end{aligned}
$$

where $w_{i}$ and $t_{i}$ are observations on accepted wages and on-going unemployment durations, $\Omega$ is the vector of parameters to be estimated, and $N_{J}$ and $N_{U J}$ denote the total number of individuals and the total number of unemployed individuals of type $\mathrm{J}$, respectively. 

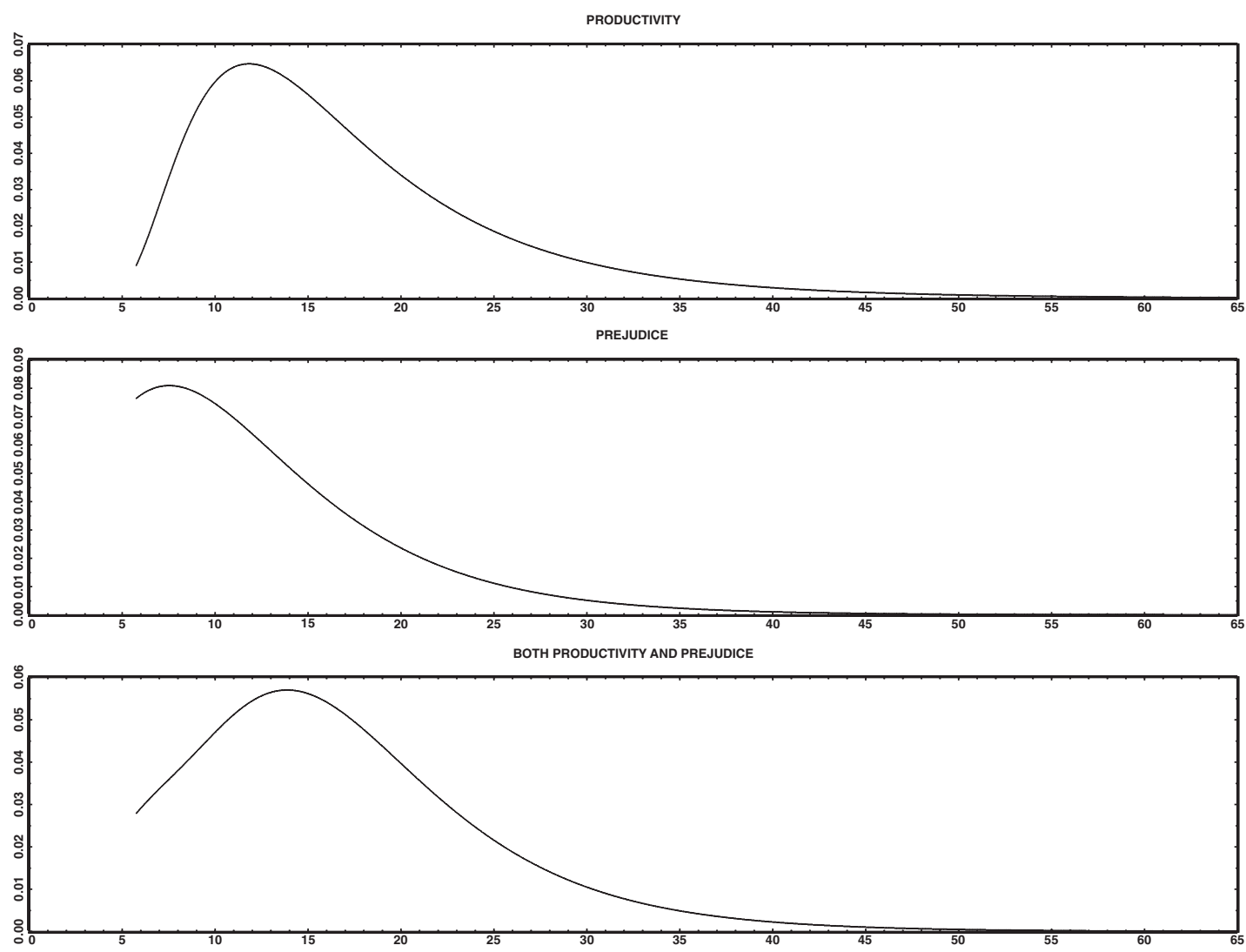

FIGURE 3

DIFFERENTIAL IMPACT OF PRODUCTIVITY AND PREJUDICE ON THE ACCEPTED EARNINGS DISTRIBUTION

\subsection{Identification Results}

4.2.1. Numerical example. An intuition of the most interesting component of the identification strategy, the separate identification of productivity differences and prejudice, can be given by analyzing whether a model with productivity differences and prejudice generates a distinctively different distribution than a model with only productivity differences. ${ }^{15}$

In this example I will focus on the implied shape of the accepted wage distribution under different model specifications. The values of the parameters used in this numerical exercise are obtained by estimating the model with gender-specific parameters. ${ }^{16}$ The results are reported in Figure 3. The top panel, labeled Productivity, shows the density of accepted wages under no prejudice, that is, $(p, d)=(0,0)$. The second panel shows the impact of prejudice: This is the shape of accepted wages in a model where all the employers are prejudiced, that is, $(p, d)=(1, \widehat{d})$. The shape is now quite different, with the increasing part of the distribution before the truncation point almost missing. It is a result of the fact that matches between women and prejudiced employers are acceptable only at relatively high productivity values, that is, when $x \geq \rho U_{W}+\widehat{d}$.

\footnotetext{
15 The identification is valid only conditioning on the functional form assumptions that will be discussed in the next section. This numerical example, only has the objective of showing that productivity differences and prejudice have a differential impact on observables once these assumptions are in place.

16 The productivity case is specification (4) in Table 2, the full prejudice case is not reported in Table 2, and both the productivity and prejudice case is specification (6) in Table 2.
} 
When the proportion of prejudiced employers is not forced to be either one or zero, the observed earning distribution is a mixture between earnings of workers employed at prejudiced employers and earnings of workers employed at unprejudiced employers. This situation is reported in the bottom panel of Figure 3, where $(p, d)=(\widehat{p}, \widehat{d})$. The shape of the density is now more similar to the top panel, but the low tail between the truncation point and the mode is less steep. This is due to the mixture between the increasing density of women working for unprejudiced employers (top panel) and the decreasing density of women working for prejudiced employers (second panel). With this mixture model, it is therefore possible to distort the distribution of accepted wages in a different way than in a model with only productivity differences or with full prejudice. The difference in shape between the top panel and the bottom panel is intuitively what allows the identification of $(p, d)$ on top of $\left(\lambda_{W}, \eta_{W}, \mu_{W}, \sigma_{W}\right){ }^{17}$

The comparison of Figures 1 and 2 shows that this is exactly the type of distortion that needs to be explained in the data for women. The empirical distribution of women's earnings with respect to men has more mass on the left tail, but the slope out of the truncation point is actually flatter.

The degree of precision in estimating $(p, d)$ depends on the density of women working at unprejudiced employers and the density of women working at prejudiced employers being well separated. The separation is entirely due to $d$ whereas the proportion in the mixture is entirely captured by $p$, generating a differential impact useful for their separate identification. An illustration of the different contribution of $p$ and $d$ to the observed wage distribution is given in Figure 4. In the left column, $p$ is fixed at 0.5 and $d$ is allowed to vary from 5 to 20; in the right column, the disutility is fixed at 15 and $p$ changes from 0.1 to 0.9 . The proportion of prejudiced employers mainly affects the mode of the distribution: An increase in $p$ (from top to bottom panel of the right column) moves the mode to the left. The disutility $d$, instead, marginally affects the mode but increasingly flattens the distribution on the left of the mode ( $d$ increases moving from top to bottom in the left column.) Therefore, out of the boundaries, the two parameters have a sufficiently different impact to guarantee a rather precise estimation. Some economic intuition behind the differential impact of $p$ and $d$ may be obtained by recalling that the disutility parameter $d$ has two impacts on the wage schedule (5): a direct impact on wages of women working at prejudiced employer and an indirect impact through the outside option $\rho U_{W}$ on women working at both a prejudiced and unprejudiced employer. The second impact is also shared by the proportion of prejudiced employers $p$, but only the first impact adds relatively more mass right above the reservation wage, contributing to flatten the distribution and generating the result illustrated in the example.

4.2.2. Formal discussion The set of parameters to be identified is denoted by $\Omega$. Before describing the identification strategy it is useful to note the following five points.

First, I will only discuss here the hardest case to identify: complete heterogeneity between men and women. Complete heterogeneity means that the only parameter men and women have in common is the discount rate $\rho$. If identification is proved under complete heterogeneity, then it is also proved for specifications where men and women have some parameters in common.

Second, the Nash bargaining coefficient $\alpha$ is a parameter notoriously difficult to identify without employer's side information, as shown, for example, in Eckstein and Wolpin (1995) and Flinn (2006). I will therefore not attempt to identify it, and I will apply a common solution in applied work by setting this parameter to one half. ${ }^{18}$ Some behavioral foundation for this value

\footnotetext{
${ }^{17}$ For completeness, recall that the reservation productivity value, that is, the lowest observed productivity, depends on the environment. Specifically, in the top panel of Figure 3 (productivity) we have $x^{*}=\widehat{w}^{*}$; in the middle panel (full prejudice) we have $x^{*}=\widehat{w}^{*}+\widehat{d}$; finally in the last panel (both prejudice and productivity) we are back to $x^{*}=\widehat{w}^{*}$ because a positive proportion of women meet unprejudiced employers. The numerical value ranges from 5.74 to 12.43

${ }^{18}$ See, for example, Eckstein and Wolpin (1993). Also Flinn and Heckman (1982), without explicitly assuming a bargaining structure, generate a wage schedule that corresponds to setting $\alpha=1 / 2$. Flinn (2006) estimates this parameter for a sample of unskilled workers-therefore likely to have a lower coefficient than the college educated workers of my sample_obtaining a value of about 0.4. The sensitivity of the estimates to the value of $\alpha$ is analyzed in Section 5.2.
} 

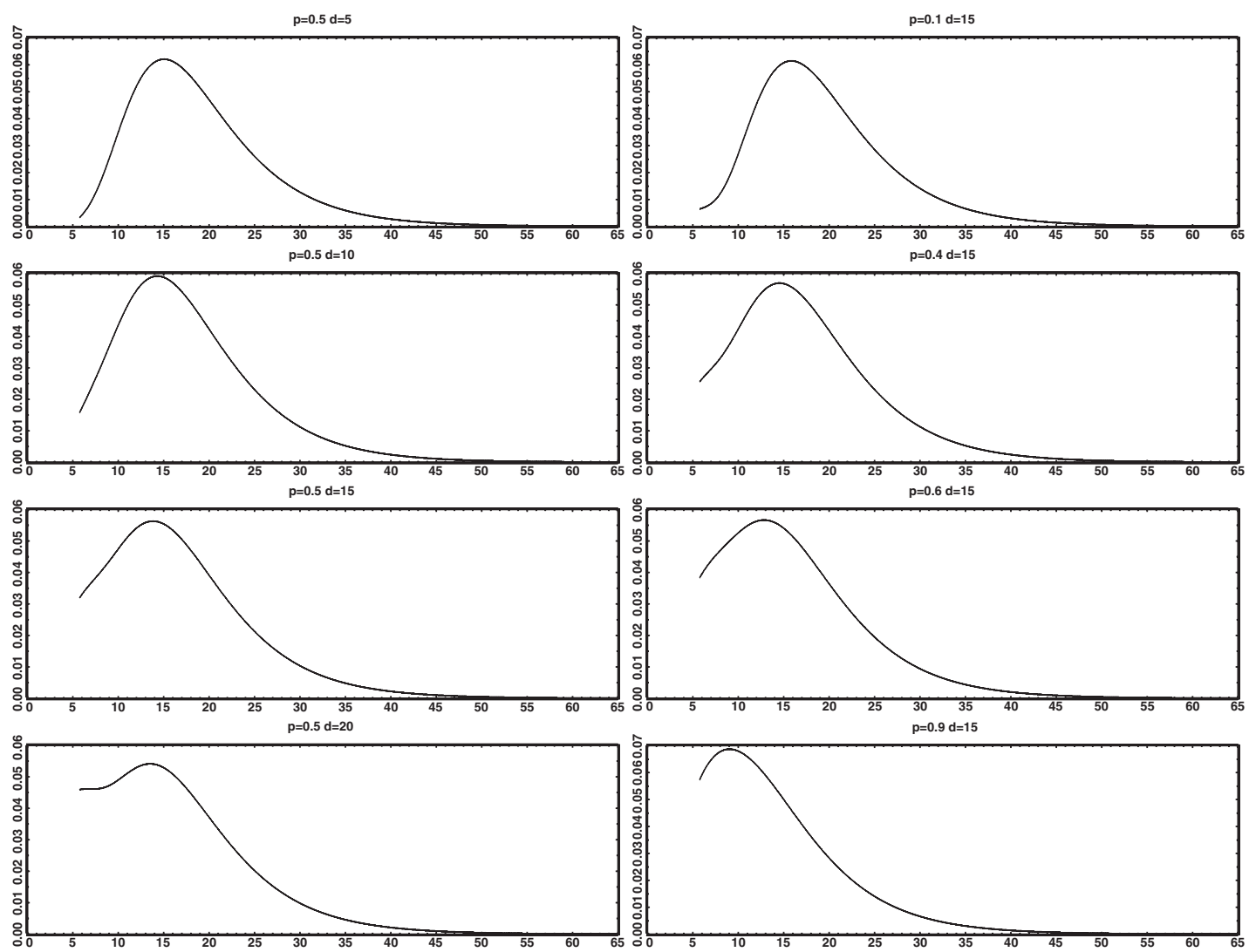

FIGURE 4

IMPACT OF CHANGE IN DISUTILITY (LEFT PANEL) AND CHANGE IN PROPORTION OF PREJUDICED EMPLOYERS (RIGHT PANEL) ON THE ACCEPTED EARNINGS DISTRIBUTION

results from assuming that a common discount rate is shared by workers and employers, leading to symmetric Nash-bargaining (Binmore et al., 1986; Binmore, 1987).

Third, the structural parameters $\rho$ and $b_{J}$ enter the log-likelihood (13) only through the reservation match-value $\rho U_{J}$ : They can therefore be only jointly identified and the model can be reparametrized in terms of $\rho U_{J}$ since $\rho$ and $b_{J}$ can be recovered by the reservation wage Equation (9).

Fourth, even if the primitive parameter is the exogenous arrival rate $\lambda_{J}$, we can reparametrize the model considering the hazard rate $h_{J}$ as the parameter to be identified because the hazard rate conditioning on the model is an invertible function of $\lambda_{J}$ as shown in Equation (10).

Fifth, a necessary condition for identification is to assume a recoverable parametric distribution for the productivity-match distribution $g_{J}(x) .{ }^{19}$ As will be explained later, to separately identify prejudice and productivity differences, it is also necessary to assume that such distribution belongs to a location-scale family. The definition of a location-scale density is

$$
g_{J}\left(x ; \mu_{J}, \sigma_{J}\right)=\frac{1}{\sigma_{J}} f\left(\frac{x-\mu_{J}}{\sigma_{J}}\right),
$$

where $f$ is a known function, $\mu_{J}$ the location parameter, and $\sigma_{J}$ the scale parameter.

${ }^{19}$ A distribution is recoverable from a truncated distribution if knowledge of the point of truncation and of the distribution above the point of truncation are enough to uniquely determine it. Flinn and Heckman (1982) show that in a search model with match-specific productivity, it is impossible to determine the shape of the productivity distribution below the truncation point (the reservation value) without a parametric assumption. This knowledge is essential to incorporate equilibrium effects in evaluating policy experiments. 
The model is now reparametrized in terms of the following set of parameters to be identified:

$$
\Omega=\left\{\begin{array}{c}
\rho U_{M}, \rho U_{W} \\
h_{M}, \eta_{M}, \mu_{M}, \sigma_{M} \\
h_{W}, \eta_{W}, \mu_{W}, \sigma_{W}, p, d
\end{array}\right\}
$$

and the identification can be described in the following five steps.

First, because $\rho U_{J}$ is equal to the reservation wage for each type of worker, $\widehat{\rho U}_{J}$ is identified by the minimum accepted wage observed in the data.

Second, the hazard rates and termination rates are identified by the unemployment rate and by unemployment durations. This follows from the first-order conditions on the log-likelihood, which imply

$$
\begin{gathered}
\widehat{h}_{J}=\frac{N_{U J}}{\sum_{i \in U_{J}} t_{i}}, \\
\widehat{\eta}_{J}=\frac{N_{U J}}{N_{E J}} \widehat{h}_{J} .
\end{gathered}
$$

Note that no information from wages is used, and therefore their identification is secured independently from the other six parameters.

Third, the parameters of the male productivity distribution $\left(\mu_{M}, \sigma_{M}\right)$ play a role only on the accepted wage distribution for men. Because wages are truncated at the reservation wage $w_{J}^{*}=\rho U_{J}$ and are a linear function of the random variable $x$ that follows the location-scale distribution $g_{M}(x)$, we can rewrite the density of accepted wages for men as

$$
\begin{aligned}
\frac{\frac{1}{\alpha} g_{M}\left(\frac{w_{i}-(1-\alpha) \rho U_{M}}{\alpha}\right)}{\tilde{G}_{M}\left(\rho U_{M}\right)} & =\frac{\frac{1}{s_{M}} f\left(\frac{w_{i}-l_{M}}{s_{M}}\right)}{\tilde{F}\left(\frac{\rho U_{M}-l_{M}}{s_{M}}\right)} \\
l_{M} & \equiv \alpha \mu_{M}+(1-\alpha) \rho U_{M} \\
s_{M} & \equiv \alpha \sigma_{M},
\end{aligned}
$$

which implies that the location and scale parameters $l_{M}$ and $s_{M}$ are identified from the sample of accepted wages $w_{i}$. Because $\alpha$ is fixed and $\rho U_{M}$ is already identified, $\mu_{M}$ and $\sigma_{M}$ are then identified by solving the two linear equations that map them into $l_{M}$ and $s_{M}$.

Fourth, the four parameters $\left(\mu_{W}, \sigma_{W}, p, d\right)$ have an impact on the accepted wage distribution for women, which can be rewritten as a sum over two truncated distributions

$$
\begin{aligned}
& \frac{\frac{(1-p)}{\alpha} g_{W}\left(\frac{w_{i}-(1-\alpha) \rho U_{W}}{\alpha}\right)}{\tilde{G}_{W}\left(\rho U_{W}\right)}+\frac{\frac{p}{\alpha} g_{W}\left(\frac{w_{i}+\alpha d-(1-\alpha) \rho U_{W}}{\alpha}\right)}{\tilde{G}_{W}\left(\rho U_{W}+d\right)} \\
& =(1-p) \frac{\frac{1}{s_{W N}} f\left(\frac{w_{i}-l_{W N}}{s_{W N}}\right)}{\tilde{F}\left(\frac{\rho U_{W}-l_{W N}}{s_{W N}}\right)}+p \frac{\frac{1}{s_{W P}} f\left(\frac{w_{i}-l_{W P}}{s_{W P}}\right)}{\tilde{F}\left(\frac{\rho U_{W}-l_{W P}}{s_{W P}}\right)},
\end{aligned}
$$


where

$$
\begin{aligned}
& l_{W N} \equiv \alpha \mu_{W}+(1-\alpha) \rho U_{W} \\
& l_{W P} \equiv \alpha \mu_{W}+(1-\alpha) \rho U_{W}-\alpha d \\
& s_{W N}=s_{W P} \equiv \alpha \sigma_{W} \equiv s_{W} .
\end{aligned}
$$

This model constitutes a mixture of two truncated distributions that share the same scale parameter. The proportion in the mixture $p$, the location parameters $l_{N W}$ and $l_{P W}$, and the scale parameters $s_{W}$ are identified for a quite large class of parametric distributions $g_{J}$ by having access to a sample of accepted wages $w_{i}$ as shown by Teicher (1963). From $l_{W N}$ we can then recover $\mu_{W}$, since $\alpha$ is fixed and $\rho U_{W}$ already identified; from $l_{W P}$ we can secure $d$, since $\mu_{W}$ is now identified. Finally, $s_{W}$ recovers $\sigma_{W}$ since $\alpha$ is fixed. Note that the identification is not limited to a mixture of two distributions, but it holds for finite mixtures, allowing for the estimation of models with more than two types of employers.

Fifth, by Equation (10) we can recover $\lambda_{J}$ and by Equation (9) we can jointly recover $\rho$ and $b_{J}$.

In conclusion, the general results from the identification strategy can be summarized as follows: (i) As in any search-matching-bargaining model, identification depends on assuming a parametric distribution for the match-specific productivity that should be recoverable from observing its truncation; (ii) to specifically identify prejudice and productivity differences, such distribution should be characterized by a location and scale parameter and should allow for the identification of its finite mixtures.

These requirements exclude some common distributions such as the Pareto-for lack of recoverability - and the exponential-for lack of a location parameter-but they still encompass a quite large class of distributions. For example, the Normal, the Gamma, and the distribution usually assumed in applied work, the Lognormal, all guarantee identification of the model.

\section{ESTIMATION}

5.1. Maximum Likelihood Estimates. Following Flinn and Heckman (1982), the estimation is in two steps. In the first step, the reservation wage is estimated by the following strongly consistent estimator: ${ }^{20}$

$$
\widehat{\rho U_{J}}=\min _{w_{i}}\left\{w_{i}, i \epsilon E_{J}\right\}
$$

Because of strong consistency, in the second step the parameters $\left\{\lambda_{J}, \eta_{J}, \mu_{J}, \sigma_{J}, p, d\right\}$ are estimated by directly maximizing a concentrated likelihood where $\widehat{\rho U_{J}}$ replaces $\rho U_{J}$ in the $\log$ likelihood (13). Notice that consistency of this estimator requires the reservation wages being equal at both employers for each worker's type. In the heterogenous model, this is still the case because employers are ex ante identical: Employers' types are revealed only upon meeting, and therefore only reservation values of the match-specific productivity will be affected. Even if identification is proved in theory, it is hard to precisely estimate $p$ if the two densities constituting (18) are not well separated (Hill, 1963). Because the separation, as measured by $\frac{l_{W N}-l_{W N}}{s_{W}}=\frac{\alpha d}{s_{W}}$, is entirely due to $d$, the lack of precise estimation in the case of small separation is fully consistent with the model: It is difficult to estimate the impact of employer's types if the types are very similar.

Estimation results are reported in Table 2. In the first three columns, arrival rates and termination rates are constrained to be the same for men and women, whereas in the last three

${ }^{20}$ That is $\sqrt{N}\left(\widehat{\rho U}_{J}-\rho U_{J}\right)$ has a degenerate distribution: Asymptotic theory is presented in Flinn and Heckman (1982). This estimator is also implemented by Bowlus (1997), Bowlus et al. (1995), and Kiefer and Neumann (1993). 
TABLE 2

MAXIMUM LIKELIHOOD ESTIMATES

\begin{tabular}{|c|c|c|c|c|c|c|}
\hline & (1) & (2) & (3) & (4) & (5) & (6) \\
\hline$\lambda$ & $\begin{array}{c}0.2220 \\
(0.0317)\end{array}$ & $\begin{array}{c}0.2247 \\
(0.0322)\end{array}$ & $\begin{array}{c}0.2280 \\
(0.0327)\end{array}$ & & & \\
\hline$\lambda_{M}$ & & & & $\begin{array}{c}0.1795 \\
(0.0392)\end{array}$ & $\begin{array}{c}0.1792 \\
(0.0391)\end{array}$ & $\begin{array}{c}0.1795 \\
(0.0392)\end{array}$ \\
\hline$\lambda_{W}$ & & & & $\begin{array}{c}0.2700 \\
(0.0510)\end{array}$ & $\begin{array}{c}0.2777 \\
(0.0528)\end{array}$ & $\begin{array}{c}0.2862 \\
(0.0545)\end{array}$ \\
\hline$\eta$ & $\begin{array}{c}0.0050 \\
(0.0010)\end{array}$ & $\begin{array}{c}0.0050 \\
(0.0010)\end{array}$ & $\begin{array}{c}0.0050 \\
(0.0010)\end{array}$ & & & \\
\hline$\eta_{M}$ & & & & $\begin{array}{c}0.0032 \\
(0.0010)\end{array}$ & $\begin{array}{c}0.0032 \\
(0.0010)\end{array}$ & $\begin{array}{c}0.0032 \\
(0.0010)\end{array}$ \\
\hline$\eta_{W}$ & & & & $\begin{array}{c}0.0077 \\
(0.0021)\end{array}$ & $\begin{array}{c}0.0077 \\
(0.0021)\end{array}$ & $\begin{array}{c}0.0077 \\
(0.0021)\end{array}$ \\
\hline$\mu$ & & $\begin{array}{c}3.4338 \\
(0.0154)\end{array}$ & & & $\begin{array}{c}3.4338 \\
(0.0154)\end{array}$ & \\
\hline$\sigma$ & & $\begin{array}{c}0.5231 \\
(0.0096)\end{array}$ & & & $\begin{array}{c}0.5231 \\
(0.0096)\end{array}$ & \\
\hline$\mu_{M}$ & $\begin{array}{c}3.4563 \\
(0.0165)\end{array}$ & & $\begin{array}{c}3.4563 \\
(0.0165)\end{array}$ & $\begin{array}{c}3.4563 \\
(0.0165)\end{array}$ & & $\begin{array}{c}3.4563 \\
(0.0165)\end{array}$ \\
\hline$\sigma_{M}$ & $\begin{array}{c}0.5578 \\
(0.0123)\end{array}$ & & $\begin{array}{c}0.5579 \\
(0.0123)\end{array}$ & $\begin{array}{c}0.5578 \\
(0.0123)\end{array}$ & & $\begin{array}{c}0.5578 \\
(0.0123)\end{array}$ \\
\hline$\mu_{W}$ & $\begin{array}{c}3.2119 \\
(0.0187)\end{array}$ & & $\begin{array}{c}3.4575 \\
(0.0589)\end{array}$ & $\begin{array}{c}3.2119 \\
(0.0187)\end{array}$ & & $\begin{array}{c}3.4546 \\
(0.0456)\end{array}$ \\
\hline$\sigma_{W}$ & $\begin{array}{c}0.5719 \\
(0.0140)\end{array}$ & & $\begin{array}{c}0.4222 \\
(0.0264)\end{array}$ & $\begin{array}{c}0.5719 \\
(0.0140)\end{array}$ & & $\begin{array}{c}0.4232 \\
(0.0235)\end{array}$ \\
\hline$d$ & & $\begin{array}{c}6.6777 \\
(3.1068)\end{array}$ & $\begin{array}{l}13.4555 \\
(2.6082)\end{array}$ & & $\begin{array}{c}6.6786 \\
(3.1054)\end{array}$ & $\begin{array}{l}13.5940 \\
(2.3602)\end{array}$ \\
\hline$p$ & & $\begin{array}{c}0.8113 \\
(0.3640)\end{array}$ & $\begin{array}{c}0.5160 \\
(0.1483)\end{array}$ & & $\begin{array}{c}0.8113 \\
(0.3633)\end{array}$ & $\begin{array}{c}0.5065 \\
(0.0988)\end{array}$ \\
\hline$N$ & 2,213 & 2,213 & 2,213 & 2,213 & 2,213 & 2,213 \\
\hline $\begin{array}{l}\ln L \\
\text { LR tests }\end{array}$ & -7898.945 & -7901.449 & -7880.325 & -7896.602 & -7899.115 & -7877.978 \\
\hline $\begin{array}{l}P \text {-value } \\
P \text {-value }\end{array}$ & 0.0000 & 0.0000 & $\begin{array}{l}0.0958 \\
0.9994\end{array}$ & 0.0000 & 0.0000 & 0.9999 \\
\hline
\end{tabular}

Notes: Asymptotic standard errors in parentheses. Data: CPS 1995; College graduate or more; 30-55 years old; white. Reservation values estimated by the minimum observed earning in the distribution of each group (bootstrap standard errors): $\widehat{w}_{W}^{*}=5.750(0.0911)$ and $\widehat{w}_{M}^{*}=7.175(0.0438)$. The first likelihood ratio (LR) test is a specification test against specification (6); the second LR test is a specification test against a specification with three types of employers.

columns they are unconstrained. Specifications (3) and (6) estimate jointly prejudice and productivity differences. For comparison, purposes and check robustness, specifications (1) and (4) estimate a model without prejudice and specifications (2) and (5) a model with prejudice and no productivity differences. Table 3 reports predicted values based on the corresponding column in Table 2.

As mentioned earlier, identification requires a parametric assumption on the productivitymatch distribution that satisfies some regularity conditions. The most common assumption in the literature is to consider the wage distribution or the match values distribution to be lognormally distributed. A visual inspection of the empirical distributions of the accepted earnings (Figures 1 and 2) suggests that this is a sensible assumption on this sample. ${ }^{21}$

\footnotetext{
${ }^{21}$ Other assumptions for the productivity distribution have been tried in estimation: the gamma distribution and the normal distribution. The best alternative has proved to be the normal distribution even if it still generates a much worse fit than the lognormal. Point estimates are very similar to a lognormal for arrival and termination rates parameters, for the parameters characterizing male productivity, and for the proportion of prejudiced employers. Female productivity parameters and the disutility parameter, instead, are much more imprecisely estimated.
} 
TABLE 3

PREDICTED VALUES

\begin{tabular}{|c|c|c|c|c|c|c|c|}
\hline & \multicolumn{3}{|c|}{$\begin{array}{c}\text { Same Arrival } \\
\text { and Termination Rates }\end{array}$} & \multicolumn{3}{|c|}{$\begin{array}{c}\text { Different Arrival } \\
\text { and Termination Rates }\end{array}$} & \multirow[b]{2}{*}{ Sample } \\
\hline & $\begin{array}{c}\text { No } \\
\text { Prejudice } \\
(1)\end{array}$ & $\begin{array}{l}\text { Full } \\
\text { Prejudice } \\
\text { (2) }\end{array}$ & $\begin{array}{c}\text { Estimated } \\
\text { Prejudice } \\
\text { (3) }\end{array}$ & $\begin{array}{c}\text { No } \\
\text { Prejudice } \\
(4)\end{array}$ & $\begin{array}{c}\text { Full } \\
\text { Prejudice } \\
(5)\end{array}$ & $\begin{array}{l}\text { Estimated } \\
\text { Prejudice } \\
\quad(6)\end{array}$ & \\
\hline \multicolumn{8}{|c|}{ Productivity } \\
\hline$E(x)$ & & $\begin{array}{l}35.54 \\
(0.538)\end{array}$ & & & $\begin{array}{l}35.54 \\
(0.537)\end{array}$ & & \\
\hline$V(x)$ & & $\begin{array}{l}397.39 \\
(21.591)\end{array}$ & & & $\begin{array}{l}397.38 \\
(21.582)\end{array}$ & & \\
\hline$E_{M}(x)$ & $\begin{array}{l}37.04 \\
(0.645)\end{array}$ & & $\begin{array}{l}37.04 \\
(0.645)\end{array}$ & $\begin{array}{l}37.04 \\
(0.645)\end{array}$ & & $\begin{array}{l}37.04 \\
(0.645)\end{array}$ & \\
\hline$V_{M}(x)$ & $\begin{array}{l}500.76 \\
(35.430)\end{array}$ & & $\begin{array}{l}500.79 \\
(35.434)\end{array}$ & $\begin{array}{l}500.77 \\
(35.432)\end{array}$ & & $\begin{array}{l}500.77 \\
(35.432)\end{array}$ & \\
\hline$E_{W}(x)$ & $\begin{array}{l}29.24 \\
(0.575)\end{array}$ & & $\begin{array}{l}34.70 \\
(1.733)\end{array}$ & $\begin{array}{l}29.24 \\
(0.575)\end{array}$ & & $\begin{array}{l}34.61 \\
(1.320)\end{array}$ & \\
\hline$V_{W}(x)$ & $\begin{array}{l}330.75 \\
(26.306)\end{array}$ & & $\begin{array}{l}234.95 \\
(20.827)\end{array}$ & $\begin{array}{l}330.74 \\
(26.304)\end{array}$ & & $\begin{array}{l}234.92 \\
(20.799)\end{array}$ & \\
\hline \multicolumn{8}{|c|}{ Earnings } \\
\hline$E_{M}(w \mid E)$ & $\begin{array}{l}22.17 \\
(0.322)\end{array}$ & $\begin{array}{l}21.39 \\
(0.267)\end{array}$ & $\begin{array}{l}22.17 \\
(0.323)\end{array}$ & $\begin{array}{l}22.17 \\
(0.323)\end{array}$ & $\begin{array}{l}21.39 \\
(0.266)\end{array}$ & $\begin{array}{l}22.17 \\
(0.323)\end{array}$ & 21.94 \\
\hline$E_{W}(w \mid E)$ & $\begin{array}{l}17.56 \\
(0.288)\end{array}$ & $\begin{array}{l}18.37 \\
(0.280)\end{array}$ & $\begin{array}{l}17.40 \\
(0.295)\end{array}$ & $\begin{array}{l}17.56 \\
(0.288)\end{array}$ & $\begin{array}{l}18.37 \\
(0.280)\end{array}$ & $\begin{array}{l}17.40 \\
(0.273)\end{array}$ & 17.41 \\
\hline \multicolumn{8}{|c|}{ Unemployment } \\
\hline$u_{M}$ & $\begin{array}{c}0.022 \\
(0.0031)\end{array}$ & $\begin{array}{c}0.022 \\
(0.0031)\end{array}$ & $\begin{array}{c}0.022 \\
(0.0031)\end{array}$ & $\begin{array}{c}0.017 \\
(0.0038)\end{array}$ & $\begin{array}{c}0.017 \\
(0.0038)\end{array}$ & $\begin{array}{c}0.017 \\
(0.0038)\end{array}$ & 0.017 \\
\hline$E_{M}(t \mid U)$ & $\begin{array}{l}4.523 \\
(0.6461)\end{array}$ & $\begin{array}{c}4.462 \\
(0.6389)\end{array}$ & $\begin{array}{c}4.403 \\
(0.6313)\end{array}$ & $\begin{array}{c}5.593 \\
(1.2205)\end{array}$ & $\begin{array}{l}5.593 \\
(1.2205)\end{array}$ & $\begin{array}{c}5.593 \\
(1.2204)\end{array}$ & 5.593 \\
\hline$u_{W}$ & $\begin{array}{l}0.022 \\
(0.0031)\end{array}$ & $\begin{array}{c}0.023 \\
(0.0032)\end{array}$ & $\begin{array}{c}0.023 \\
(0.0032)\end{array}$ & $\begin{array}{c}0.028 \\
(0.0052)\end{array}$ & $\begin{array}{c}0.028 \\
(0.0052)\end{array}$ & $\begin{array}{c}0.028 \\
(0.0052)\end{array}$ & 0.028 \\
\hline$E_{W}(t \mid U)$ & $\begin{array}{c}4.529 \\
(0.6470)\end{array}$ & $\begin{array}{c}4.602 \\
(0.6594)\end{array}$ & $\begin{array}{c}4.668 \\
(0.6706)\end{array}$ & $\begin{array}{c}3.724 \\
(0.7036)\end{array}$ & $\begin{array}{c}3.723 \\
(0.7035)\end{array}$ & $\begin{array}{c}3.725 \\
(0.7040)\end{array}$ & 3.725 \\
\hline
\end{tabular}

Notes: Predicted values from specifications (1)-(6) reported in Table 2. Asymptotic standard errors by Delta method in parentheses.

Consider first the model without prejudice: Under segmentation in the labor market, the same model is separately estimated on the two different groups of workers. Arrival rates $\left(\lambda_{J}\right)$ and termination rates $\left(\eta_{J}\right)$ are estimated to be higher for women and the estimated values for the location and scale parameters $\left(\mu_{J}\right.$ and $\left.\sigma_{J}\right)$ imply lower average productivity for women as reported in Table 3. The gap in productivity is substantial, able to replicate the average earnings differential observed in the data. This specification is comparable to Bowlus (1997) and produces quite similar results, despite differences in the data set and in the model. Bowlus also finds higher female arrival rates and termination rates and lower average female productivity. Female productivity is reported to be $17 \%$ lower in Table 5 of Bowlus (1997), a value comparable with the $21 \%$ differential in average productivity found here under specifications (1) and (4). As acknowledged by Bowlus, unobserved productivity difference is a "catchall" variable, fitting all the residual variation in the wage distributions not captured by the model including, possibly, discrimination.

Consider now the model with only prejudice. Assuming no differences in productivity, most of the wage differential must be explained by the prejudice parameters $(p, d)$. Under this model, the majority of the employers, about $81 \%$, are estimated to be prejudiced against women, with a disutility value of about $19 \%$ of the estimated average productivity. As expected, coefficients on productivity and discrimination do not change much between columns (2) and (5) because arrival rates and termination rates are mainly identified by unemployment durations. 
Finally, columns (3) and (6) report estimates of the specification in which productivity differences and explicit prejudice are jointly estimated. Results show that both components play a significant role in explaining the gender differentials we observe. Under specification (3) average female productivity, reported in Table 3 , is estimated to be $6.48 \%$ lower than male productivity and under specification (6) to be about $6.55 \%$ lower. The extent of explicit prejudice is significant in both specifications: As reported in Table 2, the estimate of $p$ implies that about half of the employers are prejudiced and the estimate of $d$ implies that disutility from hiring women is about $36 \%$ of the average male productivity. In order to give an idea of the order of magnitude of these point estimates, consider the result about race discrimination obtained by Bowlus and Eckstein (2002): They estimate the disutility from hiring black at about $31 \%$ of white productivity and the proportion of prejudiced employers at about $56 \%$.

5.2. Fit, Specification Test, and Sensitivity Analysis. The two bottom lines of Table 2 report $p$-values for likelihood ratio (LR) specification tests. The first is a test of each specification against specification (6), the second is a test of specifications (3) and (6) against a model with three types of employers: one unprejudiced and two prejudiced with potentially different parameters. The first test implies that all the restrictions are rejected, leading to the conclusion that a model with only productivity differences or only prejudice performs worse than a model in which both are present. This conclusion is also confirmed by testing specifications (1) and (2) against specification (3). The second test does not reject, respectively, specifications (3) and (6), that is, it does no reject the restriction of only two types of employers (prejudiced and unprejudiced).

A similar result is obtained by testing against a specification with four types of employers.

As a result of this LR tests, specification (6) will be the benchmark specification used to discuss the main implications of the model and to perform the policy experiments. A first sense of how well specification (6) fits the data is obtained by looking at fit on first moments, reported in Tables 3 and 4, and by comparing the predicted and empirical density of accepted earnings, reported in Figures 1 and 2.

The last two columns of Table 3 show that the fit on first moments is very good on unemployment variables and on female earnings whereas the model slightly overestimates average accepted male earnings. The last two rows of Table 5 compare the women/men ratio of average earnings, the measure commonly used to describe gender wage differentials. The ratios are computed on averages over the entire distribution, column 1, and over the bottom and top $25 \%$ quantiles, columns 2 and 3. The fit is quite good on the entire distribution because the model generates a ratio of $78.5 \%$, quite close to the $79.4 \%$ of the sample. The model is also able to generate the relative gain of female earnings as we move up on the distribution: The top $25 \%$ has a higher ratio than the bottom $25 \%$. Note that a model with only productivity differences is not able to generate this ranking, implying almost no difference in the bottom $25 \%$ and a significant differential in the top $25 \%$.

Figures 1 and 2 compare the histogram of observed earnings with the densities predicted by the model: The fit is good, in particular on female earnings. The less precise fit on male earnings is mainly due to the three mass points on the right tail of the distribution generated by topcoding on the original data. In terms of shape of the distribution, the estimated model is able to generate the crucial features of the data that were discussed in the identification, in particular the flatter low tail of the predicted female distribution.

Before moving to the post-estimation analysis, it is also useful to check the sensitivity of the estimates with respect to the main assumptions behind specification (6). The main results of the sensitivity analysis are reported in Table 4: To ease the comparison only the prejudiced parameters and the productivity differentials are reported. The estimates of the transition parameters $\left(\lambda_{J}, \eta_{J}\right)$ are almost unaffected and they are not reported.

The first sensitivity control is with respect to the Nash-bargaining coefficient $\alpha$. As mentioned, this parameter is extremely difficult to identify without demand side information and in the estimates has been fixed at 0.5 under the assumption of symmetric Nash bargaining. Table 4 reports the estimation results when $\alpha$ is fixed at different values, ranging from 0.3 to 0.7 . This 
TABLE 4

SENSITIVITY OF ESTIMATION RESULTS

\begin{tabular}{lccccc}
\hline \multicolumn{6}{l}{ Sensitivity with Respect to $\alpha$} \\
$\alpha$ & 0.3 & 0.4 & 0.5 & 0.6 & 0.7 \\
\hline$p$ & 0.547 & 0.529 & 0.507 & 0.482 & 0.446 \\
& $(0.137)$ & $(0.151)$ & $(0.099)$ & $(0.170)$ & $(0.229)$ \\
$d / E_{M}(x)$ & 0.393 & 0.379 & 0.367 & 0.357 & 0.353 \\
& $(0.060)$ & $(0.068)$ & $(0.064)$ & $(0.088)$ & $(0.128)$ \\
$E_{W}(x) / E_{M}(x)$ & 0.957 & 0.946 & 0.934 & 0.922 & 0.909 \\
& $(0.040)$ & $(0.037)$ & $(0.030)$ & $(0.032)$ & $(0.034)$
\end{tabular}

Sensitivity with Respect to the Number of Employers

\begin{tabular}{lcc}
\hline & 2 Types & 3 Types \\
\hline$p$ or $\left(p_{1}+p_{2}\right)$ & 0.507 & 0.507 \\
& $(0.099)$ & $(3.363)$ \\
$d / E_{M}(x)$ & 0.367 & \\
$d_{1} / E_{M}(x)$ & $(0.064)$ & 0.367 \\
& & $(0.244)$ \\
$d_{2} / E_{M}(x)$ & & 0.367 \\
$E_{W}(x) / E_{M}(x)$ & & $(0.399)$ \\
& 0.934 & 0.934 \\
& $(0.030)$ & $(0.036)$
\end{tabular}

Sensitivity with Respect to the Lower Truncation Point

\begin{tabular}{lcccc}
\hline Truncation & $1 \%$ & $2 \%$ & $4 \%$ & $5 \%$ \\
\hline$p$ & 0.551 & 0.533 & 0.536 & 0.507 \\
& $(0.138)$ & $(0.142)$ & $(0.163)$ & $(0.099)$ \\
$d / E_{M}(x)$ & 0.316 & 0.335 & 0.345 & 0.367 \\
& $(0.040)$ & $(0.046)$ & $(0.059)$ & $(0.064)$ \\
$E_{W}(x) / E_{M}(x)$ & 0.935 & 0.939 & 0.945 & 0.934 \\
& $(0.034)$ & $(0.034)$ & $(0.036)$ & $(0.030)$
\end{tabular}

Sensitivity with Respect to Marital Status

\begin{tabular}{lccc}
\hline & Married and Single & Single & Single No Kids \\
\hline$p$ & 0.507 & 0.509 & 0.463 \\
& $(0.099)$ & $(0.106)$ & $(0.181)$ \\
$d / E_{M}(x)$ & 0.367 & 0.511 & 0.490 \\
& $(0.064)$ & $(0.073)$ & $(0.094)$ \\
$E_{W}(x) / E_{M}(x)$ & 0.934 & 1.145 & 1.123 \\
& $(0.030)$ & $(0.063)$ & $(0.076)$ \\
\hline
\end{tabular}

Notes: Maximum likelihood estimates obtained using the same specification of column (6) in Table 2. Asymptotic standard errors in parentheses.

range of values includes the few values of Nash-bargaining coefficient estimated in the literature in reasonably similar models. ${ }^{22}$ The results show a sensitivity of the estimates to $\alpha$ and a clear monotonicity: As $\alpha$ increases the proportion of prejudiced employers decreases, the relative intensity of discrimination decreases, and the productivity differentials increases. However, the differences are relatively small and generally not statistically significant even if the range of $\alpha$ considered is relatively large.

The second sensitivity control is with respect to the number of types of employers: in the baseline specification only one prejudiced type and one unprejudiced type are assumed. As shown in Table 2, a likelihood ration test does not reject this restriction against a model in which two types of prejudiced employers with potentially two different discrimination intensity are

${ }^{22}$ Flinn (2006) estimates a value between 0.355 and 0.429 and Cahuc et al. (2006) between 0.300 and 0.635. 
TABLE 5

EARNINGS DIFFERENTIAL DECOMPOSITION

\begin{tabular}{lcccc}
\hline $\begin{array}{l}\text { Women/Men Ratio } \\
\text { Generated by }\end{array}$ & $\begin{array}{c}\text { Entire } \\
\text { Distribution }\end{array}$ & $\begin{array}{c}\text { Bottom } \\
25 \%\end{array}$ & $\begin{array}{c}\text { Top } \\
25 \%\end{array}$ & $\begin{array}{c}\text { Reservation } \\
\text { Values }\end{array}$ \\
\hline $\begin{array}{l}\text { Productivity }(\mu, \sigma) \\
\text { Prejudice }(d, p):\end{array}$ & 0.917 & 1.058 & 0.884 & 0.842 \\
$\quad$ - with spillover effects & 0.819 & 0.642 & 0.905 & 0.573 \\
$\quad$ - without spillover effects & 0.855 & 0.671 & 0.930 & 1.832 \\
Transitions $(\lambda, \eta)$ & 1.168 & 1.351 & 1.084 & \\
All parameters & & & & 0.801 \\
$\quad$ - with spillover effects & 0.785 & 0.766 & 0.814 & \\
$\quad$ - without spillover effects & 0.801 & 0.775 & 0.828 & 0.801 \\
Sample & 0.794 & 0.784 & 0.800 & \\
\hline
\end{tabular}

Notes: Women/men ratio on average accepted earnings computed over the entire distribution or over the bottom and top $25 \%$ quantiles. The last column reports the ratio of the two reservation wages. Results based on specification (6), Table 2.

allowed. Table 4 explains why: The third type of employer is estimated to be very similar to the existing prejudiced employers. In other words, the point estimates of $d$ for the two types of prejudiced employers are not significantly different. Moreover, the overall proportion of prejudiced employers is estimated to be identical to the proportion of prejudiced employers under the two-types specification.

The third sensitivity control concerns the $5 \%$ cutoff point chosen to eliminate unrealistically low hourly earnings from the estimation sample. Reservation values are directly affected by the cutoff point: They range from 3.63 for women and 4.25 for men with a $1 \%$ cutoff point to 5.75 for women and 7.175 for men with the $5 \%$ cutoff point. However, the other relevant parameter estimates are quite stable with respect to changes in the cutoff point. As shown in Table 4, with a $1 \%$ cutoff point the proportion of prejudiced employers is estimated to be $55.11 \%$, with a disutility parameter equal to about one-third of the average male productivity compared with the $50.65 \%$ and a very similar relative disutility estimated with the cutoff point at $5 \%$. In terms of estimated productivity, the ratio of average female productivity over male productivity is estimated to be $93.47 \%$ with a $1 \%$ cutoff point compared with the $93.40 \%$ estimated with the cutoff at $5 \%$. The $2 \%$ and $4 \%$ cutoff points also report very similar results. ${ }^{23}$

Finally, a fourth sensitivity control refers to a model limitation. The model does not explicitly consider other sources of group heterogeneity between men and women on top of discrimination. Empirically, specification (6) allows for all the parameters to be gender specific, and this may capture group heterogeneity in a reduced form way. A crucial source of asymmetry between men and women is family work and the different roles that men and women have in contributing to household income. Without explicitly incorporating this decision in the model, it may still be interesting to see how results change if we focus only on individuals without a family: single and single without children. The bottom panel of Table 4 reports the results of this exercise. The relative discrimination intensity and the relative productivity differential change significantly. The reason for these two changes is that both men and women have a higher productivity in this sample than in the overall sample, but the difference is larger for women than for men. The result is consistent with the literature tentatively indicating that single women are positively selected in terms of labor market performance. ${ }^{24}$ With respect to the proportion of prejudiced employers, the point estimates are instead remarkably stable: $p$ is still around $50 \%$.

\footnotetext{
${ }^{23}$ The $3 \%$ cutoff point is not reported because the cutoff coincides with a mass point of observations at 5 dollars per hour, probably due to some rounding in the raw data. This mass point exactly at the truncation point is not predicted by the model and the estimation procedure has some difficulties to fit it.

24 These results depends on demographic characteristics, human capital, and life cycle issues. Moreover, the mapping between labor market productivity and out of labor market productivity is notoriously difficult to identify, in particular for women (Blau and Kahn, 2004).
} 
The conclusion from the sensitivity analysis is that the main parameters are relatively stable with respect to these controls and that the use of specification (6) in Table 2 as the favorite specification to perform policy experiments should not be too misleading.

\subsection{Earnings Differential Decomposition. The empirical literature on discrimination often} employs wage regressions to decompose the observed wage differentials into different components, including discrimination or proxies for it. In a typical wage regression decomposition, estimated returns on productivity characteristics are separated from average endowments of these characteristics. The part of the wage differential due to difference in returns is often interpreted as discrimination. ${ }^{25}$ Based on the estimates in Table 2 and the model used to generate them, it is possible to perform a similar wage differential decomposition with the advantage that the equilibrium effects of the conterfactual experiments can be taken into account.

Table 5 presents the results of this decomposition. The table shows ratios of female average earnings over male average earnings. Each cell of each column reports the contribution of the corresponding component. For example, the first cell in the first column, labeled productivity, reports the wage differential that would arise from an environment in which men and women are identical except for productivity and there is no prejudice. Conditioning on this environment, a new equilibrium is generated and earning distributions for each type of worker are obtained. The implied earning differential, as expressed by the ratio of the average female accepted earnings over the average male accepted earnings, is the value reported in the cell. The interpretation is that the implied earning ratio can be considered the contribution of differences in productivity to the overall observed differential, once equilibrium effects are taken into account. For comparison purposes, the last row reports the ratio observed in the estimation sample. Results of the exercise are reported for ratios computed on the entire sample (first column) and on the bottom and top $25 \%$ quantiles (second and third columns) The parameter estimates used to perform the experiment are specification (6) in Table 2. When parameters are set equal for both groups, they are set at male values.

Focusing first on the entire distribution, results show that all groups of variables, except Transitions, contribute to the negative female earning differential. The parameters labeled as Transitions are the arrival rate of offer and the termination rate of the job contract. They favor women because the positive impact of the higher arrival rate more than compensate the negative impact of the higher termination rate. Prejudice generates the highest differential, even if below the value observed in the data. As expected, the lower estimated female productivity has also a significant negative impact. In order to summarize the results on the full sample, if all the difference between men and women was due to differences in productivity, the differential should be about $8 \%$; if all the difference was due to prejudice, the differential should be about $18 \%$; finally, when all the ingredients are blended together a differential of about $21 \%$ should be generated, closely matching the one observed in the data.

Looking at results on ratios of quantiles, we see that differences in productivity imply no negative differential for women at low levels of the distributions but a substantial differential as we move up in the accepted earnings distribution. On the contrary, prejudice implies that the differential decreases as wages increases. This implication matches the data ${ }^{26}$ (last row) and it is not consistent with the so called glass ceiling hypothesis. ${ }^{27}$ Women are in a relatively better position at the top of the distribution than at the bottom because the proportion of women working for prejudiced employers is lower at the top than at the bottom and women working for prejudiced employers are the ones suffering the largest wage discrimination. This is a direct result of the equilibrium wage schedule (5): The accepted wage distribution of women working

${ }^{25}$ For surveys and references, see Blau and Kahn (2000) and Altonji and Blank (1999).

${ }^{26}$ CPS data suffer from top-coding and top-coding affects male wages in higher proportion. The amount of top-coding on the estimation sample, though, seems too small to fundamentally bias moments computed on the top $25 \%$ quantile.

${ }^{27}$ The glass ceiling hypothesis states that the most important asymmetry between men and women in the labor market is the low proportion of women that reach high level—high paying jobs. Albrecht et al. (2003) also find that a glass ceiling does not seem the main determinant of the gender wage gap in the United States. 
for prejudiced employers is shifted down by the parameter $d$ so that even a relatively high match specific productivity draw generates a relatively low wage.

These results on ratios of quantiles are also another way to look at the identification. They show that the crucially different implication of productivity with respect to prejudice is not on the conditional mean but on the shape of the distribution: Productivity differences predict an higher differential as we move up in the distribution whereas prejudice predicts the opposite.

As mentioned, the model allows for spillover effects to take place and the earning differential decompositions may give an idea of the extent of their impact on the relevant labor market outcomes. When prejudice is present, is then possible to compare what the earnings differential would have been if spillover effects were not at work. The values reported in Table 5 in the row labelled without spillover effects are obtained by computing the average wage of women at unprejudiced employers shutting down the equilibrium impact of the presence of prejudiced employers, that is eliminating the impact on their outside option when bargaining with unprejudiced employers. When spillover effects are not at work the earning differentials is reduced by a relatively significant amount. For example, on the overall sample the differential decrease by about $7.5 \%$. The higher relative decrease is on the experiment where only prejudice characterize the differences between gender because it is the environment where the equilibrium impact of spillover is potentially larger. In this case, the differential decrease by about $20 \%$ on the entire distribution and by about $26 \%$ on the top percentile.

Finally, looking at the ratio of reservation wages, reported in the last column, prejudice is the component that has the strongest impact on the negative female differential, lowering the female/male ratio from about 0.8 to about 0.57 . Differences in the exogenous arrival and termination rates, instead, would predict an higher outside option for women, and productivity differentials would predict a ratio only slightly higher than the one observed in the data.

\section{POLICY EXPERIMENTS}

The gender discrimination literature has devoted a lot of attention to average wage differentials. The overall welfare of labor market participants, although, is dependent not only on average wages but on the entire wage distribution and on the dynamic of the labor market, such as the transition probabilities between states and the durations in each state. It is therefore useful to define indicators that may give a more complete description of the overall workers' welfare, taking into account at least some of the labor market dynamic.

An appropriate indicator seems a utilitarian welfare function that associates welfare value to each state occupied by individuals in equilibrium. A more detailed motivation and a complete derivation of these measures is presented in Appendix A5, but a brief definition is the following. For workers, the proposed welfare measure is the average of the value of each stateunemployment and employment at each acceptable match-specific productivity value-taken over the equilibrium distribution of types. For employers, the proposed welfare measure is the average of the per-worker utility value times the proportion of that type of workers hired in steady state.

The first column of Table 6 reports the agents' welfare measures when prejudice and productivity differences are jointly estimated. This specification is called the Benchmark Model and corresponds to the estimates reported in column (6) of Table 2. The workers' welfare values are normalized with respect to the male value, and the employers' welfare values are normalized with respect to the unprejudiced employers value. The lower panel in Table 6 shows some labor market variables related to workers' welfare.

On the workers' side, as expected, average welfare is about $24 \%$ lower for women than for men. This relative disadvantage is higher than the gap indicated by the indicators considered so far. For example, looking at the bottom panel of Table 6, average accepted earnings are about $21.5 \%$ lower for women than for men, and the reservation wage is about $19.9 \%$ lower. The ratio of reservation wages is interesting because it is also equal to the ratio of values of unemployment, which are also the ex ante value of participating in the labor market. On the employers' side, 
TABLE 6

AGENTS' AVERAGE WELFARE AND POLICIES

\begin{tabular}{lccc}
\hline & $\begin{array}{c}\text { Benchmark } \\
\text { Model }\end{array}$ & $\begin{array}{c}\text { Same } \\
\text { Productivity }\end{array}$ & $\begin{array}{c}\text { Affirmative } \\
\text { Action }\end{array}$ \\
\hline Welfare measures & & & \\
Workers & 100 & 100 & 98.53 \\
Men & 75.85 & 89.11 & 77.65 \\
Women & 88.99 & 95.04 & 89.01 \\
Overall & & & \\
Employers & 100 & 103.36 & 99.87 \\
Unprejudiced & 79.01 & 82.77 & 78.88 \\
Prejudiced & 89.37 & 92.93 & 89.22 \\
Overall & Workers' labor market variables & \\
& 7.175 & 7.175 & 7.418 \\
$w_{M}^{*}$ & 5.750 & 7.365 & 6.507 \\
$w_{W}^{*}$ & 22.17 & 22.17 & 17.79 \\
$E_{M}(w \mid E)$ & 17.40 & 20.40 & 5.597 \\
$E_{W}(w \mid E)$ & 5.593 & 5.593 & 3.714 \\
$E_{M}(t \mid U)$ & 3.725 & 3.964 & 0.018 \\
$E_{W}(t \mid U)$ & 0.017 & 0.017 & 0.028 \\
$u_{M}$ & 0.028 & 0.030 & \\
$u_{W}$ & & & \\
\hline
\end{tabular}

Notes: The Benchmark Model is specification (6), Table 2. Same productivity means women at men productivity. Affirmative action means employer receives a flow subsidy of 1 dollar per hour when hiring a woman and the subsidy is financed by a lump-sum tax on workers; the earnings reported in the lower part of the table are net of this tax. The top panel reports average welfare normalized with respect to male workers in the benchmark model and with respect to unprejudiced employers in the benchmark model.

unprejudiced employers are better off than prejudiced employers: Prejudiced employers pay in part their distaste for women but search frictions still guarantee them positive profit and utility.

Because both productivity differences and prejudice contribute to the worse performance of women in the labor market, it is interesting to isolate the impact of these two components on welfare. A rationale for this exercise can be to separate the impact of some prelabor market factors-factors that are more likely to affect the unobserved productivity represented by the $G(x)$ distribution-from some specific labor market factors-such as the presence of prejudiced employers. The experiment is similar to the one reported in Table 5 but now focusing on the overall welfare impact. The second column of Table 6 reports the results: Women and both types of employers are better off whereas men's welfare is unchanged. As expected, the result is a Pareto improvement because we are exogenously increasing the productivity of women. However, the difference in welfare between men and women is still sizable, with female welfare about $10 \%$ lower than male welfare.

A first policy that would be interesting to consider is an Equal Pay Policy. An Equal Pay Policy should require each employer to pay the same wage to workers with identical productivity. However, in the context of the model presented in the article, such a policy rises clear problems of enforcement. The main issue is that an external agent, such as the public authority responsible of enforcing the policy, cannot directly observe the match-specific value of productivity, and the measures used to proxy this productivity are often quite limited. A possible implementation can be obtained by interpreting the Nash bargaining outcome as a reduced form sharing rule where offered wages are simply an average of the wages that would be offered without the policy. However, this would constitute a major change in wage determination on top of a change in policy. An attempts to implement this policy is presented in Flabbi (2005), which shows how it generates a major improvement in women's welfare at a cost of a large reduction in employers' welfare. 
Given the previous limitations, I will focus instead on an equally relevant set of policies: Affirmative Action Policies. An Affirmative Action policy is an anti-discrimination policy that requires proactive steps (Holzer and Neumark, 2000). In the economic literature, this broad definition is very often limited to that of a quota system. ${ }^{28}$ A quota system is a specific policy where a system of numerical yardsticks for minority in hiring, federal contracts, or school enrollment are exogenously imposed.

The difference between a quota system and a more general definition of affirmative action is considered crucially important by both Holzer and Neumark (2000) in their review assessing the impact of affirmative action in the labor market and by Donohue and Heckman (1991) in their study of the impact of Civil Rights policies in improving the relative performance of blacks in the labor market. The difference between the two definitions is also considered very relevant by the last Supreme Court opinion about affirmative action. ${ }^{29}$ The Court has considered admissible an affirmative action policy of the University of Michigan Law School, but it is very careful in interpreting affirmative action not as a quota system but as "a narrowly tailored plan system" in which " race or ethnicity" may be considered "a 'plus' in a particular applicant's file."30

Whether a quota system has a significant impact in the model under consideration or not is mainly an empirical question. By looking at matching rates we expect that prejudiced employers will hire proportionally less women than unprejudiced employers, but by Corollary 2 we know that a positive proportion of women will always be hired by both types of employers. Therefore, we have to look at the actual proportions implied by the estimated values to see if imposing a quota will be effective. The estimated parameters imply that the steady-state proportions of women working at a prejudiced and unprejudiced employer are, respectively, $43.7 \%$ and $46.9 \%$, out of a population where women count for $45.6 \%$ of the labor force. In this context, any quota policy that imposes a minimum proportion of women to be hired lower than $43.7 \%$ will have no impact. This level is quite high if compared to the usual level enforced by the Equal Employment Opportunity Commission (EEOC), and it shows an environment in which the numerical yardstick is met but prejudice and its impact are unaffected.

Since at the estimated values a quota policy has a very limited impact, it may be interesting to focus on an affirmative action policy that does not explicitly use quotas and that may capture the main indications of the Supreme Court rulings. An affirmative action policy defined as a subsidy received by employers for hiring women may constitute a crude model for such a policy. More precisely, assume that employers receive a flow subsidy $\gamma$ for each woman employed, for all the time the employment relation lasts. The subsidy is paid by a lump-sum tax $t$ on all the workers. This policy is a proactive policy quite easy to implement and enforce. In spirit, it is similar to policy interventions that create incentives to hire first-seekers by lowering minimum wage requirement or other job related costs. It is also observational equivalent to other affirmative action policies implemented in practice, such as the "plus-factor" idea supported by the Supreme Court ruling. Moreover, a subsidy policy is particularly interesting in the context of this model because the impact of the subsidy is magnified by the spillover effects, now working in favor of women.

The policy affects profits and wages schedules. Defining with $\gamma$ the exogenously fixed employers' subsidy, the employers' utility will be

$$
\pi_{J I}=x-d \mathbf{I}_{\{W, P\}}-w+\gamma \mathbf{I}_{\{W\}}, \quad J=W, M ; I=N, P .
$$

\footnotetext{
${ }^{28}$ Welch (1976) is one of the first to introduce and calibrate a model to study affirmative action and he defines the policy as a quota system. Other and more recent contributions using a quota system definition are Coate and Loury (1993) and Moro and Norman (2003).

${ }^{29}$ Gratz v. Bollinger, 539 U.S. 244 (2003) and Grutter v. Bollinger, 539 U.S. 306 (2003). Both rulings are related to affirmative action policies at the University of Michigan but they are though to have a strong impact also on the labor market through the affirmative action policies that most of U.S. corporations implement.

${ }^{30}$ Excerpts from Justice O'Connor's majority opinion on Grutter V. Bollinger (Law School Case), June 24, 2003. In the same opinion, the Court explicitly states that " a race-conscious admission program cannot use a quota system."
} 
The workers' utility will be equal to the wage net of the tax

$$
w_{J I}\left(x, U_{J}\right)-t(\gamma), \quad J=W, M ; I=N, P,
$$

where $t(\gamma)$ is the endogenously determined lump-sum tax. The tax level $t$ depends on all the parameters of the model, but to simplify notation I simply emphasize the dependence on $\gamma$. The wage determination does not change. Wages are determined by Nash bargaining upon observing types and productivity, leading to the following wage schedules:

$$
\begin{aligned}
& w_{M I}\left(x, U_{M}, t\right)=\alpha x+(1-\alpha)\left[t(\gamma)+\rho U_{M}\right], \quad I=N, P, \\
& w_{W I}\left(x, U_{W}, t\right)=\alpha[x+\gamma-d \mathbf{I}(P)]+(1-\alpha)\left[t(\gamma)+\rho U_{W}\right] .
\end{aligned}
$$

The reservation values that determine the decision rules ${ }^{31}$ are

$$
\begin{aligned}
& x_{M I}^{*}=\rho U_{M}+t(\gamma), \quad I=N, P \\
& x_{W I}^{*}=\rho U_{W}+t(\gamma)-\gamma+d \mathbf{I}(P),
\end{aligned}
$$

from which we can obtain the equilibrium values of unemployment $\left(U_{W}(\gamma), U_{M}(\gamma)\right)$. The (instantaneous) value of the tax $t$ is determined by equating the total subsidy to the total tax.

The subsidy is paid by both men and women but only benefits women. Then, we expect the value to participate in the labor market to increase for women and decrease for men once the policy is implemented. This result is stated in the following proposition.

Proposition 2. For any positive subsidy $\gamma$ previously defined, the women's outside option increases and the men's outside option decreases, that is

$$
\begin{aligned}
& \frac{\partial U_{W}(\gamma)}{\partial \gamma}>0, \\
& \frac{\partial U_{M}(\gamma)}{\partial \gamma}<0 .
\end{aligned}
$$

Even if by Proposition 2 we know the impact of the policy on the values of unemployment, we cannot sign the impact on the reservation values (22). This is due to the fact that both the values of unemployment and the lump-sum tax are endogenous, and they do have an ambiguous impact on $x_{M I}^{*}$ and $x_{W I}^{*}$ as we increase the subsidy $\gamma$. What is unambiguous, instead, is the impact on the wage schedules: men's wages will be lower at any productivity values and women's wages will be higher. With respect to a pre-policy environment, women's earnings, conditioning on same $x$ and same employer type $I=N, P$, increase by

$$
w_{W I}(x, \gamma)-t-w_{W I}(x)=\alpha(\gamma-t)+(1-\alpha)\left[\rho U_{W}(\gamma)-\rho U_{W}\right]>0,
$$

where the amount is positive since $\gamma>t$ and $\rho U_{W}(\gamma)>\rho U_{W}$. The second term on the RHS is the spillover effect, now favoring women and magnifying the effect of the policy: Women get higher wages not simply because they are the only beneficiary of a subsidy that men also pay (i.e. $(\gamma-t))$ but also because their bargaining position has improved (i.e. $\left[\rho U_{W}(\gamma)-\rho U_{W}\right]$ ). For men, the opposite is true: Their lower outside option induced by the lump-sum tax reinforces the decrease in earnings.

The policy implemented on the estimated model sets the subsidy at one dollar. This is a reasonably large subsidy because it corresponds to one dollar an hour more for each woman

${ }^{31}$ It is possible that, if the subsidy is high enough, the expressions $\left(x_{W N}^{*}, x_{W P}^{*}\right)$ becomes negative. If this is the case, there is no truncation and all the matches are acceptable because the support of $x$ is $R_{+}$. I ignore this case in the text because I will only consider small enough subsidies. 
employed for all the time the employment relation lasts. It also corresponds to about $10 \%$ of the disutility parameter. Results are reported in the last column of Table 6 . The net increase in women's earning is 42 cents an hour at any level of $x$. In terms of equilibrium effects, $64 \%$ of the impact is due to sharing the tax with men and $36 \%$ is due to the spillover effect. Once again, spillover effects play a significant role.

Women's welfare increases by about 1.8 percentage points and men's welfare decreases by about 1.5 percentage points. A welfare gap remains even after this relatively generous subsidy: The reason is not simply a difference in productivity but also the presence of prejudice that still has an impact. In particular, wage discrimination is still present at prejudiced employers but it is not at unprejudiced employers. Conditioning on same productivity, women's earnings are 6.7 dollars lower than men's earning at prejudiced employers and 4 cents higher than men's earning at unprejudiced employers.

Employers' welfare is almost unaffected because both a positive and a negative impact are present. The positive impact is the presence of the subsidy and the lower outside option of men; the negative impact is the presence of the tax that increases reservation values and the higher outside option for women that reduces wage discrimination. The policy has also an impact on the quota of women hired at the two types of employers: Prejudiced employers hire a higher proportion of women than in the pre-policy setting. As expected, there is a tendency to converge to the proportion of men and women in the labor force, but changes are very small. ${ }^{32}$

To summarize, this affirmative action policy implies a redistribution of welfare from men to women, leaving employers' welfare almost unaffected. The impact is relatively modest for a subsidy of one dollar an hour, but it implies that wage discrimination is eliminated at unprejudiced employers.

\section{LIMITATIONS AND FUTURE RESEARCH}

The methodology proposed in the article describes some crucial features of the workers's labor market dynamic and leads to precise and robust estimates. However, it also has some limitations.

A first limitation concerns the employers, side of the model: It is highly stylized, taking the proportion of prejudiced employers as exogenous and potentially reducing the equilibrium effects that may be taken into account when policy experiments are implemented. An interesting extension will then be to obtain endogenously the proportion of prejudiced employers. An example is Black (1995), where a "primitive" distribution of taste for discrimination is truncated at a reservation value that depends on market conditions. An alternative, and very preliminary, contribution is Flabbi (2004), which attempts to address another limitation of the model: the lack of directed search. In Flabbi (2004), prejudiced and unprejudiced employers are seen as different sectors toward which workers may direct their search and meeting rates are endogenous. In this context, congestion effects may generate equilibria in which all types of employers survive. The use of directed search is particularly promising, because workers subject to discrimination may want to direct their search toward nondiscriminatory employers or employers may direct their search toward certain group of workers. Mailath et al. (2000) show how both equilibria with and without discrimination may arise even with ex ante identical workers once these mechanisms are in place. The main problem in the empirical implementation of these models is the asymmetry between the observable characteristics that assign workers to a given group and the only partially observable characteristics that identify prejudiced employers.

A second limitation is that labor market participation is exogenous, ignoring a decision characterized by gender asymmetries. Even if the differential in participation between men and women on the white college-graduate sample considered in this article ${ }^{33}$ is relatively small, the general issue of the different behavior of men and women with respect to labor market participation is

32 The changes in the proportion of women hired by both employers' types are in the order of 0.002 percentage points.

${ }^{33}$ CPS data on this demographic group report a participation rate of $96 \%$ for men and $82 \%$ for women. 
a relevant one. A possible way to accommodate this difference is to use data on nonparticipants to estimate a "value for nonparticipation" distribution and embed the participation decision in the search model environment. A complete treatment of labor market intermittence is much more complex and would entail extending the model to an on-the-job search environment and modeling fertility decisions and household behavior. ${ }^{34}$

A third limitation is not allowing for statistical discrimination. Statistical discrimination is an alternative theory of discrimination with respect to the taste discrimination theory adopted in the article. Focusing on only one of the two theories of discrimination is essential to obtain identification (Bowlus and Eckstein, 2002). The choice of taste discrimination has a couple of advantages: (i) the ability to differentiate between discrimination and prejudice and (ii) the prediction of wage schedules similar to the ones generated by a standard statistical discrimination model. Still, statistical discrimination remains an interesting and compelling explanation for discrimination and it has been successfully included in structurally estimated models of race discrimination (e.g., Moro, 2003). Recent interesting applications to gender discrimination are Gayle and Golan (2008) and Albanesi and Olivetti (2009). As it seems very unlikely to obtain identification of two types of discrimination and of productivity differences, one way to proceed could be to nest both types of discrimination in the same general model and then compare the empirical performance of models that incorporate only one type of discrimination.

A fourth major limitation is the necessity of functional form assumptions for identification. This limitation is common to all partial equilibrium search models, and part of the point of this article is to show that under the same assumptions it is possible to also separately identify discrimination. Still, the concern that the estimation results are sensitive to functional form assumptions is a real one, and it is only partially addressed by the sensitivity analysis presented in the article. An improvement in this direction could be working with a search model that does not require a productivity distribution assumption to obtain identification, such as the equilibrium search models based on Burdett and Mortensen (1998). The well-known problem of these models is their poor fit on the observed wage distribution: This limitation will make the identification of discrimination even harder, given its reliance on shape differences in the observed wage distribution between men and women. Progress can be made by the use of matched employer-employee data (Postel-Vinay and Robin, 2002). This direction is particularly promising for the identification of discrimination, since the wage distribution and the gender mix at each employer convey information about the employer's intensity of discrimination. However, this will require very detailed matched employer-employee data in which the entire distribution of workers at each employer can be observed. ${ }^{35}$

Finally a sixth limitation, quite common among search models, is the treatment of jobs as fully described by their wage, with no other characteristics taken into consideration. This limitation is particularly crucial when comparing men and women, because there is evidence that they may have significantly different preferences over job characteristics. The current model can partially capture this by estimating all the parameters as gender specific. For example, the lower estimated "productivity" for women may be explained in part by a different willingness to pay for job amenities. Moreover, the sensitivity section presents estimates only for a group of individuals on which the problem is less severe (single) showing robustness in the estimates of some crucial parameters. However, this is very different from explicitly taking into account which job amenities are important and are part of the bargaining process. A strong candidate is work flexibility (Altonji and Paxson, 1988). A preliminary attempt to extend an estimable search model in this direction is Flabbi and Moro (2010) where a simple binary regime of flexibility

\footnotetext{
${ }^{34}$ Without introducing fertility, a few authors have started to estimate search models with some treatment of household behavior (see, e.g., Dey and Flinn, 2008).

${ }^{35}$ Usual matched employer-employee data only allow for the observation of a limited sample of workers or some summary statistics of the firm workforce. The availability of administrative data has made the construction of data sets with a complete recording of all workers at each firm feasible if not easy. Major hurdles are privacy issues and the lack of some major covariates (as it is, for example, in the case for Italy and France, where education variables are missing). For a review, see Abowd and Kramarz (1999).
} 
is part of the labor contract within a search and bargaining framework. They are not able to estimate a comparable model for men and women, but they show that most college-educated women value flexibility and that reducing the cost of its provision may considerably reduce the gender wage gap.

\section{CONCLUSION}

By developing a search model of the labor market with matching, bargaining, and employers' taste discrimination, this article shows that it is possible to separately identify and estimate gender discrimination and unobserved productivity differences under standard functional form assumptions. The key results are obtained by exploiting the markedly different shape of the accepted earnings distribution of women and men. Prejudice is characterized as the disutility that a proportion of employers receives when hiring women. The bargaining setting generates spillover effects: The presence of some prejudiced employers lowers women's outside option with respect to men, generating wage discrimination also at unprejudiced employers. These effects have been neglected by the previous literature, and they are estimated to have a sizable impact.

Maximum likelihood estimates derived from Current Population Survey data show that both discrimination and productivity differences are present in the labor market for white college graduates. Average female productivity is estimated to be about $6.5 \%$ lower than male productivity, and about half of the employers are estimated to be prejudiced. The earning differential decomposition shows that prejudice is the most important factor in generating the difference between average accepted male and female earnings. If the difference between men and women were due exclusively to prejudice, we should observe about two-thirds of this gap; if the difference were due exclusively to productivity about one-third of this gap would remain. Both results are based on conterfactual experiments that take into account equilibrium effects.

A set of affirmative action policies is considered. An affirmative action policy implemented as a strict quota policy is shown to be not binding. More in line with the recent Supreme Court ruling, ${ }^{36}$ an alternative proactive policy is implemented. The policy, defined as an employer's subsidy for hiring women, results in a redistribution of welfare from men to women, leaving employers' welfare almost unaffected.

\section{APPENDIX}

A.1. Derivation of Value Functions (1), (2), and (6). The value of employment at a wage $w_{J I}$ for a worker $J$ is given by the following discrete time approximation where $\Delta t$ denotes a time span:

$$
W_{J}\left(w_{J I}\right)=w_{J I} \Delta t+\rho(\Delta t)\left[(1-\eta \Delta t) W_{J}\left(w_{J I}\right)+\eta \Delta t U_{J}+o(\Delta t)\right] .
$$

Expression (A.1) states that the value of employment is given by the wages received in the entire period plus the discounted expected value of remaining at the job or of falling in the unemployment state. Other possible events are happening with a negligible probability $o(\Delta t)$. Assuming $\rho(\Delta t)=(1-\rho \Delta t)^{-1}$ and because the Poisson process assumption implies that $\lim _{\Delta t \rightarrow 0} \frac{o(\Delta t)}{\Delta t}=0$, the previous expression converges to the following when $\Delta t \longrightarrow 0$ :

$$
W_{J}\left(w_{J I}\right)=\frac{w_{J I}+\eta U_{J}}{\rho+\eta} .
$$

The value of unemployment for a worker is given by the total (dis)utility from unemployment equal to $b \Delta t$ and by the the fact that after a period $\Delta t$ three main events may happen: not

\footnotetext{
${ }^{36}$ Gratz v. Bollinger, 539 U.S. 244 (2003) and Grutter v. Bollinger, 539 U.S. 306 (2003).
} 
meeting any firm, meeting a prejudiced employer, or meeting an unprejudiced employer. This process generates the following:

$$
\begin{aligned}
U_{J}=b \Delta t+\rho(\Delta t) & \left\{(1-\lambda \Delta t) U_{J}+\lambda p \Delta t \int \max \left[W_{J}\left(w_{J P}\right), U_{J}\right] d G(\theta)\right. \\
+ & \left.+\lambda(1-p) \Delta t \int \max \left[W_{J}\left(w_{J N}\right), U_{J}\right] d G(\theta)+o(\Delta t)\right\}
\end{aligned}
$$

Converging to continuous time this expression becomes

$$
\begin{aligned}
\rho U_{J}=b+\lambda & \left\{p \int \max \left[W_{J}\left(w_{J P}\right)-U_{J}, 0\right] d G(\theta)\right. \\
& \left.+(1-p) \int \max \left[W_{J}\left(w_{J N}\right)-U_{J}, 0\right] d G(\theta)\right\} .
\end{aligned}
$$

Equation (A.4) generates the equilibrium Equation (6) once the reservation value optimal decision rule and the wage schedule are inserted in it. The result is immediate once considering that

$$
\begin{aligned}
W_{J}\left(w_{J I}\right)-U_{J} & =\frac{w_{J I}+\eta U_{J}}{\rho+\eta}-U_{J}=\frac{\alpha\left(x-d \mathbf{I}_{\{W, P\}}\right)+(1-\alpha) \rho U_{J}}{\rho+\eta} \\
& =\frac{\alpha}{\rho+\eta}\left(x-d \mathbf{I}_{\{W, P\}}-\rho U_{J}\right) .
\end{aligned}
$$

\section{A.2. Proofs of Propositions and Corollaries.}

\section{Proposition 1}

Proof. Rewrite the reservation Equations (6) as

$$
x^{*}(d, p)=b+\frac{\lambda \alpha}{\rho+\eta}\left\{p \int_{x^{*}(d, p)+d}^{+\infty} \tilde{G}(x) d x+(1-p) \int_{x^{*}(d, p)}^{+\infty} \tilde{G}(x) d x\right\}
$$

where $\rho U_{W} \equiv x^{*}(d, p)$ for $0<p<1$ and $d>0$ and $\rho U_{M} \equiv x^{*}(0,0)$. I have also exploited integration by parts to rewrite $\int_{x^{*}}\left[x-x^{*}\right] d G(x)=\int_{x^{*}} \tilde{G}(x) d x$. Given the definition of $\rho U_{W}$ and $\rho U_{M}$, and given that the discount rate $\rho$ is always positive, to prove the proposition it is enough to show that

$$
\frac{\partial x^{*}(d, p)}{\partial d}<0 \text { if } 0<p<1
$$

and

$$
\frac{\partial x^{*}(d, p)}{\partial p}<0 \text { if } d>0 .
$$

To obtain the first claim, total differentiate (A.5) with respect to $d$ :

$$
\frac{\partial x^{*}(d, p)}{\partial d}=\frac{-\frac{\lambda \alpha}{\rho+\eta} p \tilde{G}\left(x^{*}(d, p)+d\right)}{1+\frac{\lambda \alpha}{\rho+\eta}\left[p \tilde{G}\left(x^{*}(d, p)+d\right)+(1-p) \tilde{G}\left(x^{*}(d, p)\right)\right]}
$$


and observe that all the parameters are positive, the survival function assumes only positive values and the numerator is negative due to the minus sign.

In order to obtain the second claim, total differentiate (A.5) with respect to $p$ :

$$
\frac{\partial x^{*}(d, p)}{\partial p}=\frac{-\frac{\lambda \alpha}{\rho+\eta}\left[\int_{x^{*}}^{x^{*}(d, p)+d} \tilde{G}(x) d x\right]}{1+\frac{\lambda \alpha}{\rho+\eta}\left[p \tilde{G}\left(x^{*}(d, p)+d\right)+(1-p) \tilde{G}\left(x^{*}(d, p)\right)\right]}
$$

and observe that all the parameters are positive, the survival function assumes only positive values and again the numerator is negative due to the minus sign.

COROLlary 1. For any equilibrium previously defined such that $0<p<1$ and $d>0$, women suffers wage discrimination and spillover effects with respect to men.

Proof. By wage schedules (4) and (5) we know

$$
\begin{aligned}
& w_{W P}(x)-w_{M P}(x)=-\alpha d+(1-\alpha) \rho\left(U_{W}-U_{M}\right)<0, \\
& w_{W N}(x)-w_{M N}(x)=(1-\alpha) \rho\left(U_{W}-U_{M}\right)<0,
\end{aligned}
$$

where both differentials are negative independently from $x$ because $d>0$ and, by proposition (2), $U_{W}<U_{M}$.

COROLlary 2. For any equilibrium previously defined such that $0<p<1$ and $d>0$, there is no complete segregation.

Proof. Men are indifferent between working for the two types of employers, and therefore they will work for both as long as both are present. Women ex ante prefer to work for unprejudiced employers, but once they meet an employer of any type they will accept to enter the match if the wage is high enough. In equilibrium, the proportion of women working for unprejudiced employers is given by the ratio of the hazard rates:

$$
P_{W N}=\frac{(1-p) \tilde{G}\left(\rho U_{W}\right)}{(1-p) \tilde{G}\left(\rho U_{W}\right)+p \tilde{G}\left(\rho U_{W}+d\right)}
$$

where $\tilde{G}(x)$ denotes the survival function $[1-G(x)]$. Complete segregation arises only if

$$
\begin{aligned}
& P_{W N}=1 \Longleftrightarrow p=0 \text { since } U_{W}<+\infty, \\
& P_{W N}=0 \Longleftrightarrow p=1 \text { since } U_{W}>0
\end{aligned}
$$

therefore, no complete segregation arises when $0<p<1$. Partial segregation of women in the unprejudiced sector arises if

$$
P_{W N}>\frac{1}{2} \Longleftrightarrow \frac{1-p}{p}>\frac{\tilde{G}\left(\rho U_{W}+d\right)}{\tilde{G}\left(\rho U_{W}\right)},
$$

that is, if the proportion of prejudiced employers is not so high to offset the lower acceptance probability induced by the higher reservation value. Partial segregation in the prejudiced sector arises if the opposite is true. 


\section{Proposition 2}

Proof. By total differentiating with respect to $\gamma$ the female value of unemployment, we get

$$
\begin{array}{r}
\rho \frac{\partial U_{W}}{\partial \gamma}=\frac{\lambda \alpha}{\rho+\eta}\left\{-p \tilde{G}\left(\rho U_{W}+t-\gamma+d\right) \frac{\partial\left(\rho U_{W}+t-\gamma+d\right)}{\partial \gamma}\right. \\
\left.-(1-p) \tilde{G}\left(\rho U_{W}+t-\gamma\right) \frac{\partial\left(\rho U_{W}+t-\gamma\right)}{\partial \gamma}\right\}
\end{array}
$$

collecting terms

$$
\begin{aligned}
& \rho \frac{\partial U_{W}}{\partial \gamma}\left\{1+\frac{\lambda \alpha}{\rho+\eta}\left[p \tilde{G}\left(\rho U_{W}+t-\gamma+d\right)+(1-p) \tilde{G}\left(\rho U_{W}+t-\gamma\right)\right]\right\} \\
& =-\frac{\lambda \alpha}{\rho+\eta}\left(\frac{\partial t}{\partial \gamma}-1\right)\left\{p \tilde{G}\left(\rho U_{W}+t-\gamma+d\right)+(1-p) \tilde{G}\left(\rho U_{W}+t-\gamma\right)\right\}
\end{aligned}
$$

every term is positive except

$$
\left(\frac{\partial t}{\partial \gamma}-1\right)<0
$$

This term is negative because the tax is on both men and women so that the increase in $t$ is always smaller than the increase in $\gamma$. This negative term cancels out with the minus sign of the RHS and we get the result. By total differentiating with respect to $\gamma$ the female value of unemployment, we get

$$
\rho \frac{\partial U_{M}}{\partial \gamma}=\frac{\lambda \alpha}{\rho+\eta}\left\{-\tilde{G}\left(\rho U_{M}+t\right) \frac{\partial\left(\rho U_{M}+t\right)}{\partial \gamma}\right\}
$$

collecting terms

$$
\rho \frac{\partial U_{M}}{\partial \gamma}\left[1+\frac{\lambda \alpha}{\rho+\eta} \tilde{G}\left(\rho U_{M}+t\right)\right]=-\frac{\lambda \alpha}{\rho+\eta} \tilde{G}\left(\rho U_{M}+t\right)\left[\frac{\partial t}{\partial \gamma}\right],
$$

where the claim is proven because all the terms are positive and there is a minus sign in front of the RHS.

A.3. Data Appendix. The estimation sample is extracted from the Annual Social and Economic Supplement (March Supplement) of the Current Population Survey (CPS) for the year 1995. The raw data files were provided by Unicon. The CPS is organized around monthly interviews with different content. The March survey focuses on work experience, income sources and amounts, non-cash benefits, health insurance, and migration and allows for the construction of unemployment durations. Information about weekly and hourly pay is collected each month on a random subset of respondents. They constitute the Earner Study and they are individuals in the last month of their four-month participation period (i.e., they are in rotation groups 4 and $8)$.

On this, some homogeneity controls are used. The sample is limited to individuals that at the moment of the interview are 30-55 years old, employed or looking for a job, white, and a college graduate or more. The age limitation is introduced to focus on individuals with mature working careers: They are reasonably homogenous in terms of working experience and are 


\begin{tabular}{lr}
\hline CPS raw data sample & 149,642 \\
Only relevant observations & $-111,784$ \\
In the 4th and 8th in-month-sample & $-19,238$ \\
In the labor force & -3243 \\
Eligible for Earner Study & \\
Homogeneity criteria & -192 \\
Employed or looking for a job & -5932 \\
Mature working career (30-55 years old) & -1372 \\
White & -5481 \\
College or more & \\
Data cleaning & -3 \\
Top-coded durations & -67 \\
Impossible to obtain hourly earnings & -6 \\
Above top-coded earnings & 2324 \\
Final sample & 1,059 \\
Women & 1,265 \\
Men & \\
\hline
\end{tabular}

NotE: Data from CPS—March 1995.

more likely to be in the steady state position assumed by the model. Only individuals employed or looking for a job are considered to exclude the category layoffs because layoffs are a labor market dynamic typically not related with the search process. Because race or ethnic group is an observable highly correlated with labor market performance, I concentrate only on the most numerous ethnic group, that is, whites. ${ }^{37}$ Education is a necessary homogeneity control because it is one of the main component of the individual human capital, and schooling is highly correlated with labor market performance. The group of college graduated or more seems the most appropriate to fit the behavior assumed in the model because a one to one bargaining is more likely to occur for skilled labor. Moreover, employers are more likely to have a direct and frequent contact with workers in skilled job positions; therefore skilled jobs are a setting in which the taste discrimination argument seems more plausible.

The first relevant variable to define the likelihood is unemployment durations. An individual unemployment duration is originally recorded in weeks and in 1995 is top-coded at 99 weeks. The estimation sample includes all the individuals satisfying the previous four criteria except the three observations with unemployment durations top-coded at 99 weeks. As standard in the search literature, the weekly unemployment durations are transformed in to monthly unemployment durations.

The second relevant variable are earnings, only observed for individuals currently employed. Earnings are recorded before deductions on an hourly or weekly basis. For some individuals both observations are available but usually only one of the two is present. I transformed all earnings in hourly earnings either using the recorded observation directly or by dividing weekly earnings for the number of hours worked per week reported by the individual. For 67 observations it is impossible to calculate hourly earnings because the number of hours worked is missing.

This background information helps in understanding the extraction process presented in Table A.1. Thanks to the high number of observations in the raw sample, the estimation sample after the homogeneity controls still contains more than 1,000 observations for both men and women.

\footnotetext{
${ }^{37}$ The classification white in the CPS is chosen by respondents out of the following alternatives: White, Black, American Indian-Eskimo, Asian/Pacific Islander, Other.
} 
A.4. Derivation of Likelihood Contributions. The subscript $J$ denotes the worker's type: $J=W, M$, and the subscript $I$ denotes the employer's type: $I=N, P$. The time homogeneity of the environment, the Poisson process that governs the arrival of job offers, and the optimal decision rule imply a constant hazard rate out of unemployment. The hazard rate is given by the probability to meet an employer times the probability to accept the match

$$
h_{J}=\lambda_{J}\left[(1-p) \tilde{G}\left(\rho U_{J}\right)+p \tilde{G}\left(\rho U_{J}+d \mathbf{I}_{\{W, P\}}\right)\right] \text {. }
$$

This hazard function uniquely determine, the distribution of complete unemployment durations: It is exponential with parameter equal to the hazard rate. The corresponding density function is

$$
f_{c}\left(t_{i} \mid J\right)=h_{J} \exp \left(-h_{J} t_{i}\right), t_{i}>0
$$

Unemployment durations in the sample have two limitations: They are the time in unemployment up to the sampling date (on-going unemployment durations) and they are observed only for individuals currently unemployed. Because the distribution of complete spells is exponential, ongoing spells are also exponential: ${ }^{38}$

$$
f_{u}\left(t_{i} \mid i \epsilon U, J\right)=h_{J} \exp \left(-h_{J} t_{i}\right), t_{i}>0 .
$$

The intuition is that the underestimation due to right censoring is compensated by the overestimation due to length bias. The second limitation is taken into account using ergodic results to weight the density by the probability of being unemployed, ${ }^{39}$ leading to the following unconditional unemployment contribution:

$$
\begin{aligned}
f_{u}\left(t_{i}, i \epsilon U \mid J\right) & =f_{u}\left(t_{i} \mid i \epsilon U\right) P(i \epsilon U) \\
& =h_{J} \exp \left(-h_{J} t_{i}\right) \frac{\eta_{J}}{\eta_{J}+h_{J}}, \quad t_{i}>0 .
\end{aligned}
$$

To consider the employed contributions, start with the unconditional cumulative distribution function of wages conditional on agents' types:

$$
\begin{aligned}
F_{e}\left(w_{i} \mid J, I\right) & =P\left(W \leq w_{i} \mid J, I\right) \\
& =P\left(\alpha\left(X-d \mathbf{I}_{\{W, P\}}\right)+(1-\alpha) \rho U_{J} \leq w_{i} \mid J, I\right) \\
& =P\left(X \leq \frac{w_{i}+\alpha d \mathbf{I}_{\{W, P\}}-(1-\alpha) \rho U_{J}}{\alpha} \mid J, I\right) \\
& =G_{J}\left(\frac{w_{i}+\alpha d \mathbf{I}_{\{W, P\}}-(1-\alpha) \rho U_{J}}{\alpha}\right) .
\end{aligned}
$$

\footnotetext{
${ }^{38}$ The result is obtained by imposing the constant hazard function on the general characterization for the density of
} ongoing unemployment spells:

$$
f_{u}(t)=\frac{\exp \left[-\int_{0}^{t} h(x) d x\right]}{\int_{0}^{\infty} s f_{c}(s) d s} .
$$

${ }^{39}$ The model without prejudice implies the following flows in and out unemployment:

$$
\frac{\partial u}{\partial t}=\eta_{J}\left(1-u_{t}\right)-\lambda_{J} \tilde{G}\left(\rho U_{J}\right) u_{t} ;
$$

therefore, in steady state

$$
\frac{\eta_{J}}{\eta_{J}+\lambda_{J} \tilde{G}_{J}\left(\rho U_{J}\right)}=u=P(i \epsilon U)
$$


The corresponding density will be

$$
f_{e}\left(w_{i} \mid J, I\right)=\frac{d F_{e}\left(w_{i} \mid J, I\right)}{d w_{i}}=\frac{1}{\alpha} g_{J}\left(\frac{w_{i}+\alpha d \mathbf{I}_{\{W, P\}}-(1-\alpha) \rho U_{J}}{\alpha}\right) .
$$

To move to the conditional density, just recall that the reservation wage for each workers' type is the same at each employers' type. Therefore, we get

$$
f_{e}\left(w_{i} \mid w_{i}>\rho U_{J}, i \in E, J, I\right)=\frac{\frac{1}{\alpha} g_{J}\left(\frac{w+\alpha d \mathbf{I}_{\{W, P\}}-(1-\alpha) \rho U_{J}}{\alpha}\right)}{\tilde{G}_{J}\left(\rho U_{J}+d \mathbf{I}_{\{W, P\}}\right)}, w_{i}>\rho U_{J}
$$

and removing conditioning on employers' type

(A.15) $f_{e}\left(w_{i} \mid w_{i}>\rho U_{J}, i \epsilon E, J\right)$

$$
\begin{aligned}
& =f_{e}\left(w_{i} \mid w_{i}>\rho U_{J}, i \epsilon E, J, N\right) P(N)+f_{e}\left(w_{i} \mid w_{i}>\rho U_{J}, i \epsilon E, J, P\right) P(P) \\
& =\frac{\frac{(1-p)}{\alpha} g_{J}\left(\frac{w_{i}-(1-\alpha) \rho U_{J}}{\alpha}\right)}{\tilde{G}_{J}\left(\rho U_{J}\right)}+\frac{\frac{p}{\alpha} g_{J}\left(\frac{w_{i}+\alpha d \mathbf{I}_{\{W\}}-(1-\alpha) \rho U_{J}}{\alpha}\right)}{\tilde{G}_{J}\left(\rho U_{J}+d \mathbf{I}_{\{W\}}\right)}, w_{i}>\rho U_{J} .
\end{aligned}
$$

Finally, conditioning only on workers' type and using ergodic results on flows in and out employment, we get

(A.16)

$$
\begin{aligned}
& f_{e}\left(w_{i}, w_{i}>\rho U_{J}, i \epsilon E \mid J\right) \\
& =f_{e}\left(w_{i} \mid w_{i}>\rho U_{J}, i \epsilon E, J\right) P\left(w_{i}>\rho U_{J} \mid i \epsilon E, J\right) P(i \epsilon E \mid J) \\
& =\left[\frac{\frac{(1-p)}{\alpha} g_{J}\left(\frac{w_{i}-(1-\alpha) \rho U_{J}}{\alpha}\right)}{\tilde{G}_{J}\left(\rho U_{J}\right)}+\frac{\frac{p}{\alpha} g_{J}\left(\frac{w_{i}+\alpha d \mathbf{I}_{\{W\}}-(1-\alpha) \rho U_{J}}{\alpha}\right)}{\tilde{G}_{J}\left(\rho U_{J}+d \mathbf{I}_{\{W\}}\right)}\right] \frac{h_{J}}{h_{J}+\eta_{J}}, w_{i}>\rho U_{J} .
\end{aligned}
$$

A.5. Welfare Measures. The proposed welfare measures exploit the steady-state equilibrium results of the model. ${ }^{40}$

In steady state, workers occupy all the possible equilibrium states: the unemployment state and the employment state at each acceptable match value $x$. An average welfare measure should associate a value at each of these states and then weigh them according to some meaningful measure. In order to clarify the discussion, define the following labor market environment $\Gamma \equiv(\lambda, \eta, \rho, b, \alpha, G(x))$. This is the environment that generates the steady-state equilibrium derived in Section 2. A function that assigns welfare values to states is

$$
T(x)=U\left[1-\mathbf{I}_{\left\{x \geq x^{*}\right\}}\right]+W[w(x, U)] \mathbf{I}_{\left\{x \geq x^{*}\right\}},
$$

where $U$ is the value of unemployment, $W[w(x, U)]$ is the value of employment at the wage that corresponds to the match value $x$, and $x^{*}$ is the reservation match value. This function assigns the value of unemployment to all the unemployed individuals $\left(x<x^{*}\right)$ and the value of being employed at a wage $w(x, U)$ to all the employed individuals $\left(x \geq x^{*}\right)$.

A meaningful weighting function for $T(x)$ is the ex post distribution of types in the population. Define with $H$ the corresponding cumulative distribution function; then $H(x)=$

\footnotetext{
${ }^{40}$ For a discussion and interpretation of this and other welfare measures in the context of a similar search model with minimum wage, see Flinn (2002b, 2006).
} 
$H(x \mid u) P(u)+H(x \mid e)[1-P(u)]$, where $u$ indicates the state of unemployment, $e$ the state of employment, and $P(e)=[1-P(u)]$. The distributions conditioning on the state are

$$
\begin{aligned}
& H(x \mid u)=\frac{G(x)}{G\left(x^{*}\right)}, x<x^{*} \\
& H(x \mid e)=\frac{G(x)-G\left(x^{*}\right)}{\tilde{G}\left(x^{*}\right)}, x \geq x^{*},
\end{aligned}
$$

and the steady-state probability to be in the unemployment state is

$$
P(u)=\frac{\eta}{\eta+h}
$$

where $h=\lambda \tilde{G}\left(x^{*}\right)$ is the hazard rate out of unemployment. The proposed welfare measure is therefore the average of the value of each state taken over the equilibrium distribution of types. Formally:

Definition 5. The average welfare measure for workers in an environment $\Gamma \equiv$ $(\lambda, \eta, \rho, b, \alpha, G(x))$ is defined as

$$
E_{H}[T(x)]=\int_{0}^{x^{*}} U \frac{\eta}{\eta+h} \frac{g(x)}{G\left(x^{*}\right)} d x+\int_{x^{*}}^{+\infty} W[w(x, U)] \frac{h}{\eta+h} \frac{g(x)}{\tilde{G}\left(x^{*}\right)} d x .
$$

This welfare measure is presented for simplicity in an homogenous environment. When heterogeneity is introduced, expression (A.18) must be specialized for each type of worker.

For men, in presence of heterogeneity, the average welfare will simply be (A.18) in an environment equal to $\Gamma_{M} \equiv\left(\widehat{\lambda}_{M}, \widehat{\eta}_{M}, \bar{\rho}, \widehat{b}_{M}, \bar{\alpha}, \widehat{G}_{M}(x)\right)$, where the estimated values correspond to the estimates of specification (6) in Table 2. For women, computation of $E_{H}[T(x)]$ under this specification is slightly more complicated, since the differential impact of the two types of employers must be taken into account. The solution is highly simplified by the fact that the proportion of prejudiced and unprejudiced employers is fixed and does not depend on $x$. Therefore, the welfare measure will simply be a linear combination of two quantities obtained by plugging in to Equation (A.18) the reservation values and wage schedules of women at the two types of employers in an environment $\Gamma_{W} \equiv\left(\widehat{\lambda}_{W}, \widehat{\eta}_{W}, \bar{\rho}, \widehat{b}_{W}, \bar{\alpha}, \widehat{G}_{W}(x), \widehat{d}, \widehat{p}\right)$.

In order to define employers' welfare, it is useful to recall the following. The model assumes search frictions, match specific productivity, and bargaining. This characterization leads to positive profit and, given the assumption on preferences, to positive utility for each type of employer. A reasonable measure of welfare is then the steady state value of this quantity.

Denote the number of workers with $N$, the proportion of men with $m$, the number of employers with $K$, and the proportion of prejudiced employers with $p$. Then, the steady-state number of male and female workers employed at each employer type are

$$
\begin{aligned}
& E_{M I}=\frac{h_{M I}}{\eta_{M}+h_{M}} m N, \quad I=N, P \\
& E_{W I}=\frac{h_{W I}}{\eta_{W}+h_{W}}(1-m) N,
\end{aligned}
$$

where $h_{J I}$ denotes the hazard rate for a type $J$ from being unemployed to being employed at an employer of type $I$. The average instantaneous utility per worker at each employers/workers match are 


$$
\begin{aligned}
& A P_{J N}=\int_{\rho U_{J}}\left[x-w\left(x, U_{J}\right)\right] \frac{g_{J}(x)}{\tilde{G}_{J}\left(\rho U_{J}\right)} d x, \quad J=M, W \\
& A P_{J P}=\int_{\rho U_{J}+d \mathbf{I}_{\{W\}}}\left[x-d \mathbf{I}_{\{W\}}-w\left(x, U_{J}, d \mathbf{I}_{\{W\}}\right)\right] \frac{g_{J}(x)}{\tilde{G}_{J}\left(\rho U_{J}+d \mathbf{I}_{\{W\}}\right)} d x .
\end{aligned}
$$

Following the previous intuition, the proposed welfare measure is the average of the per-worker utility value times the proportion of that type of workers hired in steady state.

Definition 6. The average welfare measures for employers of types $N, P$ in an environment $\Gamma \equiv(\lambda, \eta, \rho, b, \alpha, G(x), p, d)$ are

$$
\begin{aligned}
& \Pi_{N}=A P_{M N} \frac{E_{M N}}{(1-p) K}+A P_{W N} \frac{E_{W N}}{(1-p) K}, \\
& \Pi_{P}=A P_{M P} \frac{E_{M P}}{p K}+A P_{W P} \frac{E_{W P}}{p K} .
\end{aligned}
$$

The focus of interest will be the ratio $\Pi_{P} / \Pi_{N}$, so missing information on the number of employers $K$ is innocuous.

\section{REFERENCES}

Abowd, J. M., And F. Kramarz, "The Analysis of Labor Markets Using Matched Employer-Employee Data," in O. Ashenfelter and D. Card, eds., Handbook of Labor Economics, Volume 3 (Amsterdam: Elsevier Science, 1999).

Albanesi, S., And C. Olivetti, "Home Production, Market Production and the Gender Wage Gap: Incentives and Expectations," Review of Economic Dynamics 12 (2009), 80-107.

Albrecht, J., A. BJoRkLund, And S. VRoman, “ Is There a Glass Ceiling in Sweden?” Journal of Labor Economics 21(1) (2003), 145-77.

Altonj, J. G., AND R. M. Blank, " Race and Gender in the Labor Market,” in O. Ashenfelter and D. Card, eds., Handbook of Labor Economics, Volume 3 (Amsterdam: Elsevier Science, 1999).

- AND C. PAXson, "Labor Supply Preferences, Hours Constraints, and Hours-Wage Trade-offs," Journal of Labor Economics 6(2) (1988), 254-76.

Arrow, K., "The Theory of Discrimination," in O. Ashenfelter and A. Rees, eds., Discrimination in Labor Markets (Princeton, NJ: Princeton University Press, 1973), 3-33.

Becker, G., The Economics of Discrimination (Chicago: The University of Chicago Press, 1971, first ed. 1957).

Binmore, K., "Perfect Equilibria in Bargaining Models," in K. Binmore and P. Dasgupta, eds., The Economics of Bargaining (Oxford: Basil Blackwell, 1987).

- A. Rubinstein, and A. Wolinsky, "The Nash Bargaining Solution in Economic Modelling," The RAND Journal of Economics 17(2) (1986), 176-88.

Black, D., "Discrimination in an Equilibrium Search Model," Journal of Labor Economics 13(2) (1995), 309-34.

Blau, F., AND L. Kahn, “Gender Differences in Pay,” Journal of Economic Perspectives 14(4) (2000), 75-99.

- AND — - "Understanding International Differences in the Gender Pay Gap," Journal of Labor Economics 21(1) (2003), 106-44.

— AND — - "The US Gender Gap in the 1990s: Slowing Convergence," NBER Working Paper 10853, 2004.

Bowlus, A., "A Search Interpretation of Male-Female Wage Differentials," Journal of Labor Economics 15(4) (1997), 625-57.

— - AND Z. ECKSTEIN, "Discrimination and Skill Differences in an Equilibrium Search Model," International Economic Review 43(4) (2002), 1309-45.

— , N. Kiefer, and G. Neumann, "Estimation of Equilibrium Wage Distribution with Heterogeneity," Journal of Applied Econometrics 10 (1995), S119-131.

Burdett, K., And D. Mortensen, “ Wage Differentials, Employer Size, and Unemployment,” International Economic Review 39(2) (1998), 257-73.

Cahuc, P., F. Postel-Vinay, And J.-M. Robin "Wage Bargaining with On-the-Job Search: Theory and Evidence," Econometrica 74(2) (2006), 323-64. 
CAIN, G. C., "The Economic Analysis of Labor Market Discrimination," in O. Ashenfelter and R. Layard, eds., Handbook of Labor Economics (Amsterdam: North-Holland, 1986)

Coate, S., And G. C. Loury, "Will Affirmative-Action Policies Eliminate Negative Stereotypes?" American Economic Review 83(5) (1993), 1220-40.

Dey, M., AND C. FlinN, “An Equilibrium Model of Health Insurance Provision and Wage Determination," Econometrica 73 (2005), 571-627.

— AND — , "Household Search and Health Insurance Coverage," Journal of Econometrics 145(1-2) (2008), 43-63.

Donohue, J., and J. Heckman, "Continuous Versus Episodic Change: The Impact of Civil Rights Policy on the Economic Status of Blacks," Journal of Economic Literature 29(4) (1991), 1603-43.

ECKSTEIN, Z., AND É. NAGYPÁL, "US Earnings and Employment Dynamics 1961-2002: Facts and Interpretation," Federal Reserve Bank of Minneapolis Quarterly Review 28(2) (2004), 10-29.

—, AND K. Wolpin, "Duration to First Job and the Return to Schooling: Estimates from a SearchMatching Model," The Review of Economic Studies 62(2) (1995), 263-86.

— , AND — , "Estimating the Effect of Racial Discrimination on First Job Wage Offers," The Review of Economics and Statistics 81(3) (1999), 384-92.

Flabbi, L., "Gender Discrimination Estimation in a Search Model with Matching and Bargaining," IZA Discussion Paper 1764, 2005.

_ , "Taste Discrimination in a Search Model with Free-Entry," paper presented at the 2005 ESPE Conference (Paris, France), 2004.

— , AND A. Moro, "The Effect of Job Flexibility on Female Labor Market Outcomes: Estimates from a Search and Bargaining Model," IZA Discussion Paper No. 4829, 2010.

FuinN, C., "Labor Market Structure and Inequality: A Comparison of Italy and the U.S.," Review of Economic Studies 69(3) (2002a), 611-45.

_- "Interpreting Minimum Wage Effects on Wage Distributions: A Cautionary Tale," Annales d'Economie et de Statistique 67/68 (2002b), 309-55.

__ " "Minimum Wage Effects on Labor Market Outcomes under Search, Bargaining and Endogenous Contact Rates," Econometrica 73 (2006), 1013-62.

- AND J. HeCKMAn, "New Methods in Analyzing Structural Models of Labor Market Dynamics," Journal of Econometrics 18 (1982), 115-68.

Gayle, G.-L., AND L. Golan, "Estimating a Dynamic Adverse-Selection Model: Labor-Force Experience and the Changing Gender Earnings Gap 1968-93," Mimeo, Carnegie-Mellon University, 2008.

Heckman, J. J., "Detecting Discrimination," Journal of Economic Perspective 12(2) (1998), 101-16.

HiLl, B. M., "Information for Estimating the Proportions in Mixtures of Exponential and Normal Distributions," Journal of the American Statistical Association 58(304) (1963), 918-32.

Holzer, H., AND D. Neumark, “Assessing Affirmative Action,” Journal of Economic Literature 37 (2000), 483-568.

Jovanovic, B., "Job Matching and the Theory of Turnover," Journal of Political Economy 87(5) (1979), 973-90.

Kiefer, N. M., and G. R. Neumann, "Wage Dispersion with Homogeneity: The Empirical Equilibrium Search Model," in H. Bunzel, P. Jensen, and N. Westergard-Nielsen, eds., Panel Data and Labor Market Dynamics (Amsterdam: Elsevier Science, 1993).

Mailath, G., L. SAmuelson, AND A. Shaked, "Endogenous Inequality in Integrated Labor Markets with Two-Sided Search," American Economic Review 90(1) (2000), 46-72.

Moro, A., "The Effect of Statistical Discrimination on Black-White Wage Inequality: Estimating a Model with Multiple Equilibria," International Economic Review 44(2) (2003), 467-500.

- AND P. NoRman, "Affirmative Action in a Competitive Economy," Journal of Public Economics 87 (2003), 567-94.

Phelps, E., "The Statistical Theory of Racism and Sexism," American Economic Review 62 (1972), 659-61.

Postel-VINAY, F., AND J.-M. RoBIN, "Equilibrium Wage Dispersion with Worker and Employer Heterogeneity," Econometrica 70(6) (2002), 2295-350.

Teicher, H., "Identifiability of Finite Mixtures," The Annals of Mathematical Statistics 34(4) (1963), 1265-9.

Welch, F., "Employment Quotas for Minorities," Journal of Political Economy 84(4) (1976), S105-39.

Wolpin, K. I., "Estimating a Structural Search Model: The Transition from School to Work," Econometrica 55(4) (1987), 801-17. 